\title{
CRÍTICA DE GÉNERO. E. 1027: EILEEN GRAY VS. LE CORBUSIER EN CAP MARTIN
}

\author{
CARlos L. Marcos \\ Universidad de Alicante
}

Recibido: 09/02/2011

Aceptado: 20/05/2011

\section{Resumen}

La villa E.1027 ha permanecido durante años en un segundo plano en las historiografías del Movimiento Moderno a pesar de su sofisticada modernidad y su sabio entendimiento del lugar; tal vez por su crítica sutil a los principios de la modernidad instaurados en los años 20 e impuestos durante las décadas siguientes. Este ominoso olvido ha incluido también a una mujer, Eileen Gray, a quien corresponde la mayor parte de su autoría. Le Corbusier no fue ajeno ni a lo uno ni a lo otro. El artículo analiza el comportamiento del maestro en su obsesión y posterior ocupación de la Maison en bord de mer y su entorno próximo, tratando de desvelar las causas que probablemente animaron a su profanación; y finaliza con la crítica de género que premonitoriamente Gray desplegó en la E.1027 respecto del canon corbusierano ya en 1926.

Palabras Clave: Crítica, ocupación, género, Gray, Le Corbusier, E. 1027 


\begin{abstract}
The villa E.1027 has remained silenced for years in the historiography of modern architecture despite its sophisticated modernity and its wise understanding of the locus; perhaps due to its subtle criticism over the modern principles established during the 20 's and imposed over the following decades. This ominous oblivion has also included a woman, Eileen Gray, responsible for most of its authorship. Le Corbusier was not alien to either of them. This article analyzes the master's behaviour regarding his $o b-$ session and subsequent occupation of the Maison en bord de mer and its surroundings, trying to uncover the causes that probably encouraged their desecration. It ends up summarizing Gray's gender criticism presciently unfolded in E.1027 regarding corbusieran canon as early as 1926 .
\end{abstract}

Keywords: Criticism, occupation, gender, Gray, Le Corbusier, E. 1027 
Le Corbusier's «shack» [Cabanon] has been lovingly kept as a small museum, looked after the Commune of Roquebrune and visited by students and admirers of a glorious moment of modern architecture. A few yards away one of the purest examples of the same period is slowly dying.

Peter Adam (1989) ${ }^{1}$.

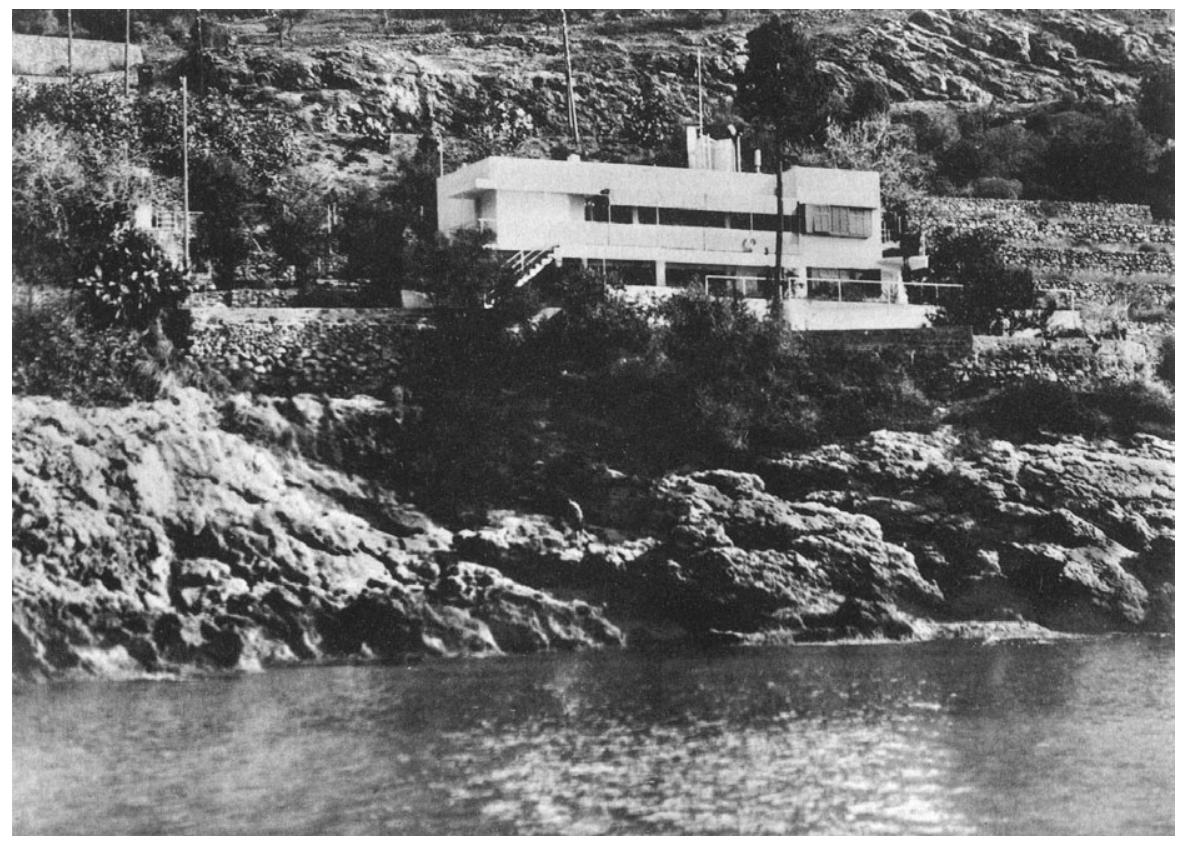

Fig. 1. E.1027 vista desde el mar.

(foto publicada en L'Architecture Vivant, 1929)

1. ADAM, Peter, 1989, «Eileen Gray and Le Corbusier», 9H, 8, p. 150-153. Afortunadamente hoy la vivienda ha sido restaurada.

Feminismo/s 17, junio 2011, pp. 259-295 
Durante la década prodigiosa del Movimiento Moderno en arquitectura, entre 1926 y 1929, Eileen Gray proyectó y construyó una villa, la E. 1027 ó Maison en bord de mer, para sí y para Jean Badovici en Cap Martin, Roquebrune. En 1952 Le Corbusier construyó una pequeña cabaña, el cabanon, a escasos 20 metros ladera arriba y hacia el este de la villa diseñada por su rival en una posición dominante sobre ella. Está sería solamente una de las muchas acciones encaminadas a la ocupación, apropiación, manipulación, alteración o desfiguración que Le Corbusier ejercería sobre una obra de arquitectura; una obra que desde luego no le dejó indiferente. Una extraña mezcla entre admiración, envidia, desprecio o machismo -acaso un poco de todo ello-, marcaría la historia de una de las obras más sofisticadas de la arquitectura del período de entreguerras, pero ¿por qué?

Analicemos primero los actos para intentar desvelar las causas. Esta peque$\tilde{n} a$ historia ya ha sido narrada de diversas formas y con distintas intensidades en otros textos ${ }^{3}$, pero en estas líneas intentaremos analizar el comportamiento de Le Corbusier en lo referente a la E.1027 y la propia vivienda como arquitectura crítica, en muchos aspectos con un incipiente canon capitaneado por el propio arquitecto, así como las causas que pudieron llevar a éste a terminar con una actitud hostil hacia la casa, como objeto, y hacia sus propietarios y diseñadores, como sujetos.

\section{Contexto de la obra}

Jean Badovici era arquitecto, crítico y editor de la influyente revista LArchitecture Vivant. Como tal, fue también uno de los protagonistas en difundir las obras y escritos de algunos de los arquitectos de la modernidad en los diez años durante los que se publicaron los 21 números de la revista. Entre ellos, Le Corbusier ocuparía un lugar muy destacado; algo que conviene tener presente en el contexto que nos ocupa. La influencia que ejercía Le Corbusier sobre él era, desde el principio, la de una autoridad en la materia.

2. La participación de Jean Badovici en el diseño de la vivienda es imprecisa y forma parte del misterio o la ocultación que por parte de la historiografía o de la crítica de arquitectura ha envuelto este baluarte de la modernidad. En principio, y como quedará justificado en el texto, parece claro que el mayor protagonismo se deba a Eileen Gray aunque Badovici también debió participar al menos en el asesoramiento de los aspectos más técnicos, a tenor de sus respectivas formaciones.

3. Ver p. ej., «E. 1027: The Nonheroic Modernism of Eileen Gray» de Caroline Constant, «Líneas de Batalla: E. 1027» de Beatriz Colomina, «Eileen Gray and Le Corbusier» de Peter Adam o «Occupying E.1027: Reconsidering Le Corbusier's «Gift» to Eileen Gray» de Jasmine Rault, al margen de biografías como las del propio Adam o la exhaustiva y estupenda monografía sobre la E.1027, Aires Modernos, de Carmen Espegel. 
Badovici animó a Eileen Gray a dedicarse a la arquitectura -más allá de su actividad como interiorista por la que era reconocida en el París de los años 20- entablando con ella una doble relación profesional y personal desde 1924 que duró varios años y que desembocaría en el encargo de la E. 1027. Como bien apunta Espegel ${ }^{4}$, la actitud de Badovici no fue desinteresada ya que vio en ella a una diseñadora de gran talento y con los recursos económicos suficientes como para materializar sus propias ideas.

Para entender todas las claves de esta historia de atracción, odio y deseo, en la que se entremezclan las relaciones personales y la atracción por un objeto, la Maison en bord de mer, resulta imprescindible considerar la génesis del proyecto y el valor afectivo que Eileen Gray otorgaba a dicho objeto. No se trataba de un encargo cualquiera para un cliente sin más. Era la primera oportunidad de construir una obra de arquitectura con arreglo a las convicciones más íntimas y los anhelos de diseño de una morada que lo sería para ella misma y para su amante ${ }^{5}$, con quien compartía buena parte de sus ideales concernientes a la arquitectura. Gray y Badovici se enrolan en la aventura de proyectar y construir una residencia en colaboración siendo con ello clientes y autores al mismo tiempo. La intensidad e intimidad de su propia relación y de ambos para con el proyecto da nombre a la propia vivienda ${ }^{6}$. Sólo así puede entenderse, entre otras cosas, que siendo el propio Badovici arquitecto y editor amigo de buena parte de los arquitectos de mayor prestigio en aquel momento y estando comprometido con la vanguardia arquitectónica, decidiera sin embargo, realizar el encargo a una interiorista sin apenas experiencia en el campo de la arquitectura ${ }^{7}$. A no ser que, razones sentimentales aparte,

4. ESPEGEL, Carmen. Heroínas del espacio. Mujeres arquitectos en el Movimiento Moderno. Ed. Generales de la Construcción. Valencia, 2006, p. 105. Quiero agradecer públicamente los comentarios y sugerencias recibidas por parte de Carmen Espegel para la redacción final de éste artículo; sin duda sus acertados consejos y su conocimiento sobre la materia han contribuido a mejorarlo.

5. Respecto de la bisexualidad de Eileen Gray, Espegel escribe «Su anhelo de independencia era demasiado fuerte como para conformarse con un mero intercambio familiar dependiente de obligaciones matrimoniales. Durante toda su vida evitó el matrimonio o cualquier otro tipo de relación duradera. Tuvo algunas relaciones íntimas tanto con hombres como con mujeres [...]» (ESPEGEL, Carmen, 2006, Op. cit., p. 97).

6. El código E. 1027 responde a un mensaje cifrado: E por Eileen, 10 por la «J» de Jean, 2 por la «B» de Badovici, y 7 por la «G» de Gray, como es bien conocido y recogido en toda la bibliografía sobre la vivienda.

7. Además del proyecto teórico con el que Gray se inició en la arquitectura a partir del modelo de la Villa Moissi (diseñada por Loos y expuesta en el Salon d'Automne de 1923, exposición en la que participaba también Gray), y su colaboración en la decoración de la renovación de algunas viviendas en Vézelay junto con Badovici precisamente en 1926 (el año en el que se proyecta la E.1027) el único proyecto arquitectónico de Gray anterior a 


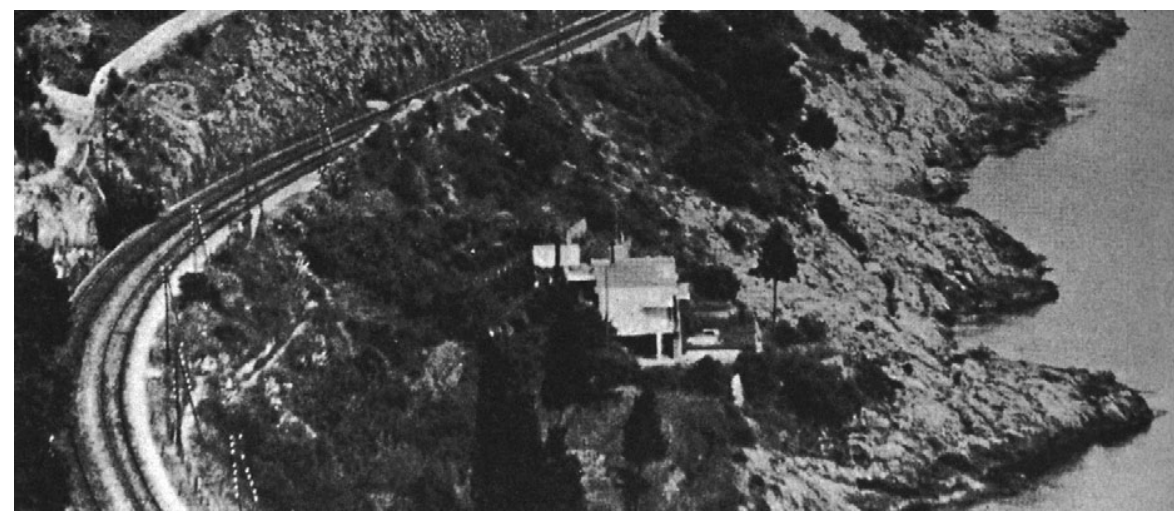

Fig. 2. E.1027 en el entorno aislada por dos límites:. (Detalle de foto de la época publicada en Aires modernos, Carmen Espegel)

quisiera ejercer sobre ella una actitud paternalista y de control sobre lo proyectado que habría sido imposible de practicar en otro caso.

Así, a finales de 1926 Eileen Gray recibe el encargo de buscar un lugar para proyectar y construir la E.1027. Esta es otra de las características que añaden un valor afectivo a la morada: su ubicación ha sido cuidadosamente escogida por la arquitecto, un rincón del paraíso de la riviera francesa, en las proximidades de Montecarlo. Este es el primer acto de apropiación del lugar; no es aventurado decir que es la primera decisión de proyecto. A diferencia de lo que sucede en un encargo convencional en el que el cliente posee una parcela y contacta con el arquitecto para que haga un proyecto para él y ese lugar, aquí es el propio arquitecto quien elige cuidadosamente el lugar. Apenas accesible, a escasos metros del mediterráneo, en una lengua de terreno aislada por la doble condición de límite entre el litoral y la vía férrea ladera arriba (Fig. 2), una parcela abancalada se asoma hacia el mediodía para conquistar el horizonte marino. La intención de aislamiento es clara; su vinculación con el mar intencional e inevitable.

\section{Le Corbusier y la E. 1027: una atracción fatal}

Le Corbusier mantenía una relación fluida con Badovici, quien había publicado algunas de sus viviendas y sus escritos en la revista L'Architecture Vivant.

la maison en bord de mer es su proyecto no construido de Casa para un Ingeniero, también desarrollado en ese mismo año. (CONSTANT, Caroline. "The Nonheroic Modernism of Eileen Gray», Journal of the Society of Architectural Historians, Vol. 53, Nº 3 (Sep. 1994), pp. 265-279). 
Eileen Gray conoció a Le Corbusier por mediación de Badovici; estaba al tanto de su arquitectura y sus escritos a través de la revista, las exposiciones parisinas y la publicación de L'Esprit Noveau. De hecho, los interiores de las viviendas que reformaría en Vézelay junto a Badovici incluían un repertorio formal y de detalles similares a los de los proyectos de Le Corbusier, como la casa Citrohan, aunque es probable que buena parte de dicha influencia fuera más una imposición por parte de Badovici, como bien señala Constant ${ }^{8}$ :

Unlike her House for an Engineer, in which Gray explored variations on Le Corbusier's spatial formulas, each of Vézelay interiors incorporated formal devices borrowed directly from his Maison Citrohan: a double height living room overlooked by a mezzanine, accessed by a narrow ship's stair and lined with pipe railings. Badovici may have mandated such adherence to Corbusieran forms to fulfil his avant-garde objectives.

Como interiorista, el trabajo de Eileen Gray tenía el suficiente vigor, personalidad y originalidad como para no depender de las imitaciones. Desde el momento en que tuvo ocasión de proyectar arquitectura, su libre interpretación de los preceptos corbusieranos estuvo patente. La tan escasa como exquisita arquitectura de Gray $^{9}$ es, de hecho, una obra compleja en la que los límites entre arquitectura, interiorismo y mobiliario se diluyen, y en la que varias de las distintas corrientes dentro del Movimiento Moderno quedan sabiamente integradas.

Por otro lado, Le Corbusier fue uno más del elenco de personajes de la cultura que frecuentaron la E. 1027 por invitación de Badovici y Gray, quienes gustaban de recibir a personas de la cultura en su Villa de la costa azul ${ }^{10}$.

Gray, Badovici y Le Corbusier fueron tres arquitectos unidos por un destino que acabaría confluyendo en un objeto arquitectónico: la Maison en bord de mer. Puede que un repaso de los hechos que enhebran la relación de los

8. Constant, Caroline. Op. cit., p. 269.

9. Rykwert, el primer crítico que se hace eco del valor de su arquitectura años después, se refiere en estos términos a la obra arquitectónica de Eileen Gray: «For an architectural oeuvre two houses, a few interiors and some unexecuted projects might seem excessively modest. In the particular case of Eileen Gray the modest quantity is in sharp contrast to extraordinary quality: quality high enough to set her among the masters of the modern movement however condensed her accomplishment.» (RYKWERT, Joseph. «Eileen Gray: two Houses and an Interior, 1926-1933», Perspecta, Vol. 13/14 (1971), pp. 67-73).

10. «Entre los numerosos invitados que visitan la casa se encuentran Christian Zervos, Fernand Lèger, Claude Roger-Marx, y Rex Martienssen. Picasso parece haber conocido la casa por medio de Le Corbusier, como cita Stanislaus von Moos en «Mariage des Contours», Oppositions 19/20, Invierno/primavera 1980.» (EPEGEL, Carmen. Aires modernos. E. 1027: maison en bord de mer Eileen Gray y Jean Badovici 1926-1929. Madrid, Ed. Mairea Libros, 2010. n.p.p. V, p. 8). 
tres para con la villa, ordenados cronológicamente, alumbre las causas por las que Le Corbusier pasó de la admiración al rechazo y de éste al deseo del objeto en sí.

Tenemos evidencia de la alta estima en que Le Corbusier tenía inicialmente a la E. 1027 por una carta ${ }^{11}$ fechada en abril de 1938 que dirigió a la propia Eileen Gray después de pasar unos días en la villa:

Me produce una gran alegría comunicarte lo mucho que esos pocos días pasados en vuestra casa me han hecho apreciar el espíritu particular que dicta toda la organización, interna como externa, y que da a los muebles -al equipo- una forma tan digna, tan encantadora, tan llena de espíritu. ${ }^{12}$

En el tono elogioso de la carta Le Corbusier apunta ya a algunas características que hacen de la E. 1027 una obra singular dentro de la modernidad: la integración entre el diseño interior y el exterior, así como la combinación del mobiliario y el equipamiento ${ }^{13}$ en un conjunto coherente a todas las escalas. Refiriéndose a esa misma carta Colomina añade: «En 1938, el mismo año en el que fue a pintar el mural Graffite à Cap-Martin, Le Corbusier había escrito una carta a Eileen Gray, en la que no solamente reconoce la única autoría de ella, sino también cuánto le gusta la casa». Algo que, en lo referente a la autoría, resulta bastante evidente a la vista de los interiores diseñados por Gray con anterioridad así como su propia vivienda estival realizada unos pocos años después en Castellar, a pocos kilómetros de Cap Martin, Tempe à Pailla ${ }^{14}$.

11. Citada por AdAm, Peter. Eileen Gray, Architect/designer: A Biography (Rev. Ed.). Londres, Ed. Thames and Hudson, 2000 (1987), pp. 309-310 y referida en varios textos sobre la E.1027. (La traducción al español es la que aparece en la monografía sobre la E.1027 de Carmen Espegel).

12. Esta carta, que iba acompañada por una pequeña acuarela del maestro, produjo una gran satisfacción personal en Eileen por lo que tenía de reconocimiento por parte de uno de los arquitectos de mayor prestigio y proyección internacional del momento, a quien ella había admirado. (ADAM, Peter, 1989, «Eileen Gray and Le Corbusier», Op.cit, p. 150).

13. La casa estaba equipada con una serie de instalaciones que conviene tener presentes en contexto temporal -1926-1929- en el que se proyecta y edifica la vivienda: frigorífico eléctrico, depósito de agua con filtro Pasteur-Chamberland, calefacción y, por supuesto, los entonces ya habituales de fontanería, electricidad y sanitarios, etc. (EsPegel, Carmen, Aires Modernos, Op. cit.).

14. Esa ambivalencia en la sexualidad y la relación de Gray y Badovici queda subrayada por el hecho de que el terreno en el que se edificó la segunda y última obra construida de Eileen Gray, su vivienda estival Tempe à Pailla, lo adquirió ella misma ya durante la construcción de la E.1027 (RAULT, Jasmine. «Occupying E.1027. Reconsidering Le Corbusier's «Gift» to Eileen Gray, Space and Culture, Vol. 8, 2 (May 2005), pp. 160-179). 
Así, la «casa llena de sentido arquitectónico» ${ }^{15}$, como Le Corbusier se refería a ella, pronto pasaría a ser un objeto de polémica. Cuando en 1938 Le Corbusier comenzó a pintar los murales en la vivienda la relación entre Gray y Le Corbusier se quebró. La intromisión de la mano de Le Corbusier en su diseño contó con la desaprobación de Gray desde el principio y, al parecer, no volvió a pisar la vivienda desde aquél momento. Si bien, rota su relación sentimental con Badovici desde hacía años y estando la propiedad a nombre de éste, no podía hacer nada para evitar que Le Corbusier «regalara» los murales a su propietario pintándolos, eso sí, sobre las paredes de una vivienda que no había diseñado él; una vivienda cuya construcción, para más desdicha, había financiado la propia Gray ${ }^{16}$, y cuya severa estética en clave de abstracción geométrica tenía bastante poco que ver con el figurativismo de dichos murales.

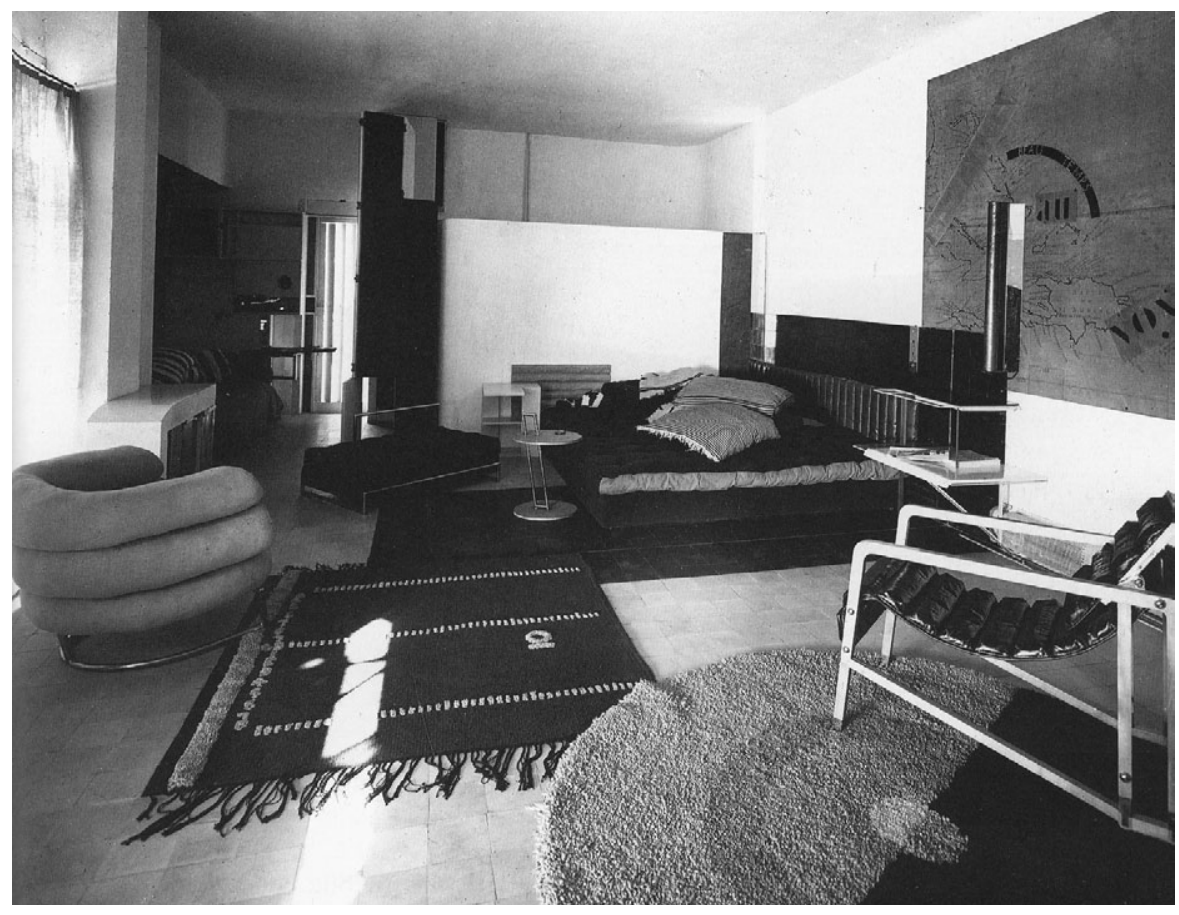

Fig. 3. Estar de la E.1027.

(foto publicada en Eileen Gray, Architect/designer: A Biography, Peter Adam)

15. AdAM, Peter, 1989, «Eileen Gray and Le Corbusier», Op. cit., p.150.

16. Tal y como lo describe Adam, «In 1956 Jean Badovici died, he had not made a will. The house, built and paid for by Eileen, was in his name.» (ADAM, Peter. Eileen Gray, Architect/designer: A Biography Op. cit., p. 152). 
Si analizamos el acto mismo de pintar los frescos sin apasionamientos, es decir el origen de la afrenta de Le Corbusier, si hay en ello un ultraje al menos tanta culpa debe atribuírsele a Badovici. En realidad, nadie pinta un fresco en una pared que no es suya dentro de un recinto privado a no ser que reciba permiso para hacerlo, o incluso sea alentado a ello; algo que parte de la historiografía reciente, quizás por sus propios prejuicios, parece olvidar. Badovici, ya contaba con un mural que el propio Le Corbusier había realizado en 1935 en su vivienda de Vézelay, como respuesta a otro mural ejecutado por Leger en la misma vivienda el año anterior. Poco después y antes de que Le Corbusier comenzara con la colonización pictórica de algunos de los muros de la E.1027, en 1937, Badovici ${ }^{17}$ escribía en estos términos sobre los trabajos murales realizados por Leger y Le Corbusier: «assembled before the courtyard wall [...] an idea ocurred to us all: THAT OF THE DESTRUCTION OF WALLS BY PAINTING, crowning, above all, the architecture to come». Sin embargo, aún pensando así sobre el papel de los frescos en los muros respecto de la obra de arquitectura, no tuvo ningún reparo en que Le Corbusier colonizara algunas de las paredes de la E.1027 con su imaginería emparentada con la estética del Picasso de la época.

La afrenta de Le Corbusier radicaba inicialmente en dos cuestiones: por un lado la más grave, consistente en la ejecución de uno de sus murales sobre un fresco de Gray en la entrada de la casa, y, por otro, en el hecho de que aún conociendo el papel de Eileen Gray en la autoría de la E.1027 no le pidiera, al menos, su parecer al respecto, como colega de profesión. Para eso tendría que haberla considerado como tal, cosa que resulta mucho suponer a tenor de su comportamiento. Así lo describe Adam ${ }^{18}$ :

Eileen had never bee asked for permission. When she found out she fell into a deep depression and rage. She considered it an act of vandalism. A fellow architect simply defaced her pure conception. After that she could never bring herself to stay in the house.

Pero la actitud un tanto ambigua de Badovici para con el oscuro objeto de deseo del maestro suizo no es únicamente un acto cobarde sino que también tiene otro tipo de motivaciones. Después de todo, Le Corbusier, por aquel entonces, no era sólo un arquitecto mundialmente reconocido; su actividad como pintor tampoco pasaba precisamente desapercibida. Los murales tendrían un valor nada desdeñable que iría incrementándose con el paso del tiempo.

17. BADOVICI, Jean, «Peinture Murale ou Peinture Spatiale.», L'Architecture d'Adjourd'hui, 8, no, 3 1937, (Cit. por Constant, Caroline, Op. cit., p. 278.).

18. AdAm, Peter. Eileen Gray, Architect/designer: A Biography, Op. cit., p. 151. 
Así, el editor y amigo de Le Corbusier no sólo consentiría que éste le regalara los frescos sino que muy probablemente lo animó a hacerlo, como bien apunta Constant ${ }^{19}$ a propósito de una carta fechada en 1941 del propio Badovici redactada poco después de un bombardeo sufrido en la zona:

As with the Vézelay murals, Badovici not only sanctioned but encouraged Le Corbusier's pictorial intervention at E.1027. His eagerness to comply with Corbusian polemics may have led Badovici to ignore the incongruities between this pictorial dissolution of the wall and Gray's more constructive integration of architecture and the decorative arts. However contrary to Gray's architectural intentions, the Roquebrune murals brought Badovici a considerable pleasure, as he recounted to Le Corbusier after surveying the limited damage his house sustained under the Italian bombardment: «Your frescoes more luminous and beautiful than ever. Intact $»^{20}$.

Así, es fácil entender que, después de todo, Le Corbusier también sintiera, en cierto sentido, menospreciado su trabajo, dado que la polémica que duraría durante el resto de sus días, estaba en bastante medida generada por el propio Badovici y él no había recibido pago alguno por unos frescos a pesar de que, sin duda, tendrían un gran valor. Desde el punto de vista de Le Corbusier, él sólo había pintado unos frescos como regalo a su editor. Esta consideración de los murales como regalo queda bien acreditada en más de una ocasión. A ello se refiere Colomina ${ }^{21}$ en estos términos:

Como todos los colonizadores, Le Corbusier no pensó en ello como invasión, sino como regalo. Es sintomático que, recapitulando el trabajo de su vida cinco años antes de morir, escriba sobre Argel y Cap-Martin en los siguientes términos: «Desde 1930, L-C dedicó doce años a un estudio ininterrumpido de Argel y su futuro. (...) Durante dichos años, preparó sin ningún coste siete grandes propuestas (siete enormes estudios)». Y más adelante escribe, «1938-1939. Ocho pinturas murales realizadas sin ningún coste en la casa de Badovici y Helen Gray en Cap-Martin». No charge for the discharge. Eileen Gray se sintió traicionada: le habían desfigurado hasta el nombre. Y renombrar es, después de todo, el primer acto de la colonización.

En efecto, Le Corbusier siempre consideró los frescos como un regalo pero, como bien sabía él mismo, en arquitectura todos los gestos adquieren significación. En el marco referencial del lugar, el espacio y el tiempo de la E.1027 su

19. Constant, Caroline, Op. cit., Ibidem..

20. BADOVICI, Jean, carta a Le Corbusier, fechada el 2 de julio de 1941, Fundación Le Corbusier (Cit. por Constant, Caroline, Op. cit., p. 278.).

21. Colomina, Beatriz. «Líneas de Batalla: E. 1027», Pasajes, $2^{\circ}$ semestre 2001, Univ. de Buenos Aires. Centro de Estudios Amancio Williams., pp. 47-55, (publicado en versión inglesa «Battle Lines: E.1027», en AGREST, Diana, ABRAMS, Harry (ed.), The Sex of Architecture, 1996, pp. 54-55). 
actividad adquiría una fuerza simbólica que, en contraste con la pureza y sencillez geométrica que animaban el diseño original, se veía incluso potenciada. Los frescos colonizaban los muros y paredes de la villa tanto como el propio Le Corbusier colonizaba y hacía en parte suya la E.1027. Es frente a esa apropiación a la que responde Gray con mayor disgusto. Pero no en menor medida por la arrogancia que demostraría Le Corbusier en lo concerniente a este asunto. Haciendo gala de su proverbial chovinismo alimentaría la polémica algún tiempo después cuando, con motivo de la edición de su Obra Completa en 1946, en las imágenes en las que aparecían los frescos de la E.1027 ni siquiera se mencionaba el nombre de Eileen Gray ${ }^{22}$. Proceder que repetiría dos años después en L'Architecture d'Aujourd'hui en un número especial dedicado a su obra. Los comentarios publicados ${ }^{23}$ un tanto despectivos hacia el valor de los muros seleccionados para ser animados con su pincel consiguieron enfurecer más aún a Gray.

En 1949, en una carta de Le Corbusier a Badovici, el primero hace una crítica bastante más explícita a propósito de la arquitectura de la E.1027, concretamente respecto del biombo que ralentiza el acceso a la gran sala de la vivienda y que actúa como límite del vestíbulo una vez en el interior de la villa: «Os aconsejo desmontar de la sala ese cacharro de contrachapado que no es más que un pseudo e ilusorio compañero del de la zona de ducha. Vuestra pieza se transformará y la entrada será totalmente distinta $»^{24}$. El límite al que se refiere, cuidadosamente diseñado como el resto de la villa, además de servir de gabanero y sombrerero crea un ámbito de privacidad añadida al entrar en el interior de la vivienda aunque la escala de la totalidad de la sala se percibe, no obstante, gracias a que dicho biombo -a caballo entre una pieza de mobiliario y un tabique bajo- no llega a tocar el techo.

Por otro lado, este elemento forma parte del ritual de entrada a la vivienda, enormemente elaborado en el diseño original, que se vincula a las propias inscripciones que Gray repartió por distintas estancias de la casa haciendo referencia explícita no tanto a su función como a la manera de utilizar cada uno de los elementos que integraban el diseño de la misma. Concretamente a la inscripción «Entrez Lentement» (entrar lentamente) que acompaña el

22. CONSTANT, Caroline, Op. cit., Ibidem.

23. «The walls chosen to receive nine large paintings were the most colourless and insignificant. In this way the beautiful walls have remained and the indifferent ones have become interesting... This villa that I animated with my paintings was very beautiful, white on the interior, and it could have managed without my talents.» LE CORBUSIER, «Unité», L'Architecture d'Adjourd'hui, 19, (número monográfico dedicado a Le Corbusier), 1948.

24. Espegel, Carmen, Heroínas del espacio, Op. Cit., n.p.p. 13, p. 128. 
elaborado rito de ingreso bajo la marquesina de entrada matizado por otra «sense interdit» (dirección prohibida); el biombo (épine-paravent) simplemente alarga dicho ritual un poco más. Al mismo tiempo, dicho biombo sirve para dividir la circulación en el interior de la sala separando el ambiente de la sala principal del pequeño comedor. Por último, en el recorrido de ingreso el biombo dirige finalmente la mirada del visitante hacia el mar que la sinuosa entrada a la vivienda se ha encargado de esconder para provocar un efecto sorpresa hacia las espléndidas vistas, una vez alcanzado el interior de la misma.

Sin embargo, de todas las consideraciones que se pueden hacer a propósito de la ocupación de la vivienda por parte de Le Corbusier relacionadas con la realización de los frescos, sin duda la más dolorosa debió ser la ejecución del fresco de la entrada sobre otro que la propia Eileen Gray había ejecutado en el mismo paramento. Aquí cobran todo el sentido las apreciaciones de Adam quien compara la ejecución de los polémicos frescos con una auténtica «violación» ${ }^{25}$. El desprecio olímpico por lo diseñado por Gray es aquí manifiesto. Siendo discutible la acción de Le Corbusier sobre las paredes neutras de la E.1027 -si es que acaso hay alguna pared que pueda serlo- mucho más lo es la ejecución de un fresco sobre otro. A este fresco de la entrada se refiere Espege ${ }^{26}$ en los siguientes términos:

Ya en el interior del zaguán surge la elección entre la puerta principal y la entrada de servicio. En su frente, la pared que oculta la escalera de caracol «gran muro desnudo aunque neto y claro, [que] sugerirá la idea de resistencia», está pintada con un fresco con motivos geométricos que incluye dos inscripciones [...] (se desconoce el trazado de dicho fresco ya que en 1939 Le Corbusier realizó otro sobre este mural, en el que únicamente mantuvo las dos inscripciones del original de Eileen Gray: Sense Interdit y Entrez Lentement).

25. AdAm, Peter, Eileen Gray, Architect/designer: A Biography, Op. cit.,p. 311. De hecho las comparaciones con la actitud de Le Corbusier con un acto de violencia sexual han producido una serie de textos algo más recientemente pretendiendo adentrarse en implicaciones psicoanalíticas que poco tienen que ver con la crítica de arquitectura y que -quizás por sus prejuicios ideológicos- caricaturizan la actitud de Le Corbusier y la polémica en torno a los frescos, perdiendo con ello la debida objetividad crítica. En ninguno de ellos se menciona el valor indiscutible de los frescos o el hecho de que fuera el propio Badovici quien consintiera e incluso alentará al propio Le Corbusier a pintarlos y, lo más llamativo, la destrucción del fresco original de carácter geométrico que Eileen Gray pintó en la entrada de la E.1027 -el acto más reprobable de todos ellos- tampoco se denuncia.

26. Espegel, Carmen, Aires modernos, Op. Cit., p. 28 y n.p.p. 4, Ibidem. El entrecomillado corresponde al texto del número monográfico de L'Architecture Vivante de otoñoinvierno de 1929, E.1027: Maison en bord de mer y el texto entre paréntesis a la nota a pie de página del texto de Carmen Espegel. 
La coherencia formal que alumbra todo el diseño de la E.1027 desde los menores detalles, pasando por el mobiliario y las artes decorativas hasta la escala de la propia arquitectura se veía drásticamente alterada ante la rotundidad formal de los frescos y su estética figurativista. Además de los diseños en alfombras, cortinas y demás elementos cuidadosamente diseñados e incluso tejidos por la propia Gray en clave inequívoca de abstracción geométrica, se ha conservado el collage que preside la pared norte de la gran sala en el que se integran elementos funcionales, el mobiliario y el propio collage en una partitura polifónica: «Affixed to the wall by a light fixture and holding shelves, this collage exemplified an important principle for Gray: the inseparability of painting and architecture -a view shared with the early adherents of De Stijl $\gg^{27}$. En efecto, a pesar de que el diseño de Gray resulta difícil de catalogar, las afinidades con la arquitectura neoplasticista parecen incluso más claras que los preceptos funcionalistas de Le Corbusier. Podemos imaginar que el fresco destruido por Le Corbusier estuviera animado de la misma estética.

Le Corbusier probablemente veía en su regalo un equivalente -salvando las distancias- de la intervención de Miguel Ángel con sus frescos en la Capilla Sixtina por los que hoy es conocida mundialmente dicha obra de arquitectura, pero es evidente que Eileen Gray no percibía la actuación de Le Corbusier en los mismos términos. Lo que sin duda empezaba a preocupar más a Le Corbusier a estas alturas de la polémica era la posible destrucción de sus frescos que -además de tener un gran valor objetivo- para él tenían un valor afectivo mucho mayor. El tema del desnudo femenino le había atraído desde al menos 1927 y como él mismo confesaría tenía una cierta predisposición a «desnudar» las figuras femeninas para comprender mejor cuál era su constitución formal ${ }^{28}$. Durante años estuvo haciendo y rehaciendo unos estudios para unos desnudos que había empezado en Argel $^{29}$. La belleza ${ }^{30}$ de

27. Constant, Caroline, Op. cit.,p. 271..

28. ZAKNIC, Ivan, «Le Corbusier Sans Fin», Journal of Architectural Education, Vol. 42, 3 (Spring 1989), pp. 49-59.

29. «Nuestras andanzas por las calles laterales nos llevaron al final del día a la calle Kataroudji, donde él [Le Corbusier] quedó fascinado por la belleza de dos jóvenes muchachas, una española y la otra argelina. Ellas nos condujeron por una escalera estrecha a su cuarto: allí dibujó algunos desnudos en -para mis sorpresa- un bloc escolar de dibujo con lápices de colores. Los bocetos de la joven española, tanto acostada sola en la cama como agrupada bellamente con la argelina, eran bellos y realistas, pero él dijo que no eran buenos y se negó a mostrarlos», Carta de Jean de Maisonseul a Samir Rafi, fechada el 5 de enero de 1968 (cit. por ColominA, Beatriz., Op. cit. p. 48).

30. Quizás no sólo fue la belleza de las dos mujeres sino algo más relacionado con algún tipo de experiencia sexual que le dejó marcado de por vida. Parece evidente que las dos 
las dos figuras obsesionó a Le Corbusier durante años quien estuvo dibujando y redibujando estudios a partir de ellas que con el tiempo acabaría uniendo a su interpretación personal del cuadro de Delacroix, Femmes d'Alger Dans leur appartement, tal y como lo recoge Colomina ${ }^{31}$ : «Pero pronto ambos proyectos se solaparon: Le Corbusier modificó los gestos de las figuras de Delacroix, haciéndolos coincidir gradualmente con las figuras de sus propios bocetos. Le Corbusier afirmó que habría llamado a esta composición final Las Femmes de la Casbah». Sin embargo, la versión final no llegó a ver la luz hasta que, según Colomina, Le Corbusier realizara uno de los murales en la E.1027, el conocido como Sous les pilotis o Graffite à Cap-Martin ${ }^{32}$ a partir de dichos bocetos. La reelaboración a lo largo de años de esos dibujos da buena cuenta
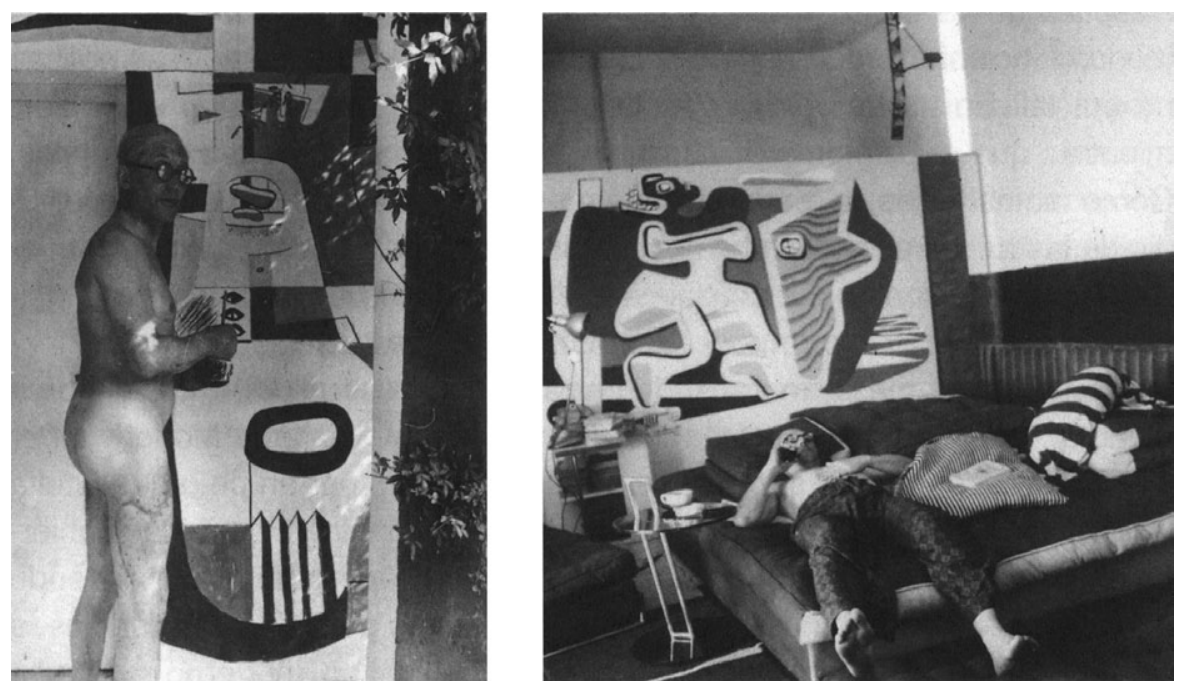

Figs. 4 y 4 bis. Dos murales de Le Corbusier en la E.1027.

(fotos publicadas en Aires modernos, Carmen Espegel)

mujeres desconocidas debieron ofrecer algo más que posar desnudas para Le Corbusier y Maisoneul si se observan las poses -algunas de ellas abiertamente sexuales- de los dibujos de Le Corbusier (Ver el catálogo Le Corbusier Secret de la Ahrenberg Collection), aunque la discreción del relato sea parca al respecto.

31. Colomina, Beatriz. «Líneas de Batalla: E. 1027», Op. cit. p. 49.

32. Respecto de este mural pintado en el exterior en la terraza cubierta bajo la gran sala de la vivienda al que también se refería su autor como Trois Femmes, según el testimonio de Mme. Schelbert, Le Corbusier «explicó a sus amigos que 'Badou' [Badovici] estaba representado a la derecha, su amiga Eileen Gray a la izquierda, y el contorno de la cabeza y el pelo de la figura sentada en el centro, decía, era 'el hijo deseado y nunca nacido'» cit. por ColominA, Beatriz. Op. cit. Ibidem. 
del valor afectivo y la importancia que Le Corbusier atribuía a los frescos de la E.1027 como parte de esa larga investigación pictórica sobre la que llevaba años trabajando.

Por otro lado, si se observa el contenido geometrismo del diseño de Gray es evidente que, desde un punto de vista exclusivamente estético, el figurativismo -aun siendo de carácter abstractivo-, el tratamiento cromático y la potencia formal de los frescos poco o nada tienen que ver con la pureza y sencillez formal de la E.1027. El propio Badovici llegaría a amenazar a Le Corbusier con destruirlos para restaurar el sentido del diseño original alterado por la intervención del maestro suizo. La correspondencia de la época entre Badovici y Le Corbusier demuestra cómo sus relaciones se habían deteriorado notablemente a propósito de los polémicos frescos. Como ha apuntado Caroline Constant en su magnífico artículo, ya le había costado bastante conseguir fotos de los mismos para su publicación, que Badovici le facilitó más bien a regañadientes cuidando de recortar las imágenes para evitar que mostraran su contexto en el espacio arquitectónico. Le Corbusier volvió a pedirle a Badovici más fotografías de los frescos que también incluyeran el contexto espacial de la vivienda, fotos que no acababan de llegar. Una ansiedad creciente a la vista del cariz que debieron tomar los acontecimientos -quizás ante la sospecha de que los murales que tanto apreciaba su autor fueran finalmente eliminados para restaurar el diseño original de la vivienda- fue apoderándose de Le Corbusier. Ante las presiones de Gray para que Badovici conminara a Le Corbusier a deshacer lo hecho, finalmente Badovici escribió en una carta fechada el 30 de diciembre de $1949^{33}$ que el biógrafo de Eileen Gray, Peter Adam, sugiere que pudo dictar ella misma:

What a narrow prison you have built for me over a number of years, particularly this year through your vanity. On the contrary, my attitude toward you has been nothing but joyful and full of happy trust -seven volumes of the heroic era of LArchitecture Vivante. My hut [baraque] served [you] as a testing ground by sacrificing the profound direction of an attitude that formally banished painting. As purely functional architecture, that was its strength for such a long time: 1925. And you have denied its absolute character with such harshness in your writings, disseminating them through your world-wide authority. You lack of generosity toward me. A correction from you seems necessary, if not, I will be forced to do it myself, thus to re-establish the original spirit of the house by the sea.

La contestación a la carta de Badovici no se hizo esperar, iestá fechada al día siguiente! Además de la ironía malintencionada con la que contestaba a

33. Cit. por Constant, Caroline, Op. cit., pp. 278-279. 
las insinuaciones de Badovici ${ }^{34}$ era bastante consciente de que, como sugiere Adam, la carta debió ser idea de Gray porque, además, Le Corbusier amenazaba con hacer público el debate en el plano de la arquitectura con un comportamiento arrogante e impropio de su condición, incluyendo también en ella la vivienda que Gray se había construido para sí en Castellar, Tempe à Pailla, sin ninguna colaboración de Badovici, por lo que resulta inequívoca la estructura profunda del mensaje así como el destinatario real de su contenido:

Quieres un juicio mío basado en mi autoridad mundial para mostrar -si entiendo correctamente tus pensamientos más íntimos-, para demostrar 'la calidad de la arquitectura pura y funcional' que has puesto de manifiesto en la casa de Cap-Martin y que ha sido destruida por mis intervenciones pictóricas. OK, envíame algunos documentos fotográficos de esa manipulación de puro funcionalismo... Envíame también algunos documentos de [la casa de] Castellar, ese submarino del funcionalismo; entonces yo expondré a la luz de todo el mundo este debate.

Todo lo anterior ha tratado de contextualizar la polémica con el nivel de detalle suficiente como para entender los hechos y las motivaciones que se triangulan en torno a los tres arquitectos. Sorprendentemente, la ocupación de Le Corbusier no fue únicamente pictórica. Incluyó también varios episodios de manipulación e intervenciones en el plano arquitectónico que quizás resulten tan interesantes como reveladoras a propósito de la fijación que vinculó fatalmente a Le Corbusier con la E.1027 y con el privilegiado lugar en el que se asentaba. Sobre todo si se comparan con la elegancia de la Maison en bord de mer.

La primera intervención arquitectónica que Le Corbusier planeó en las inmediaciones de la E.1027 data precisamente de 1949 -el año de la ruptura-; sus primeros croquis para Robert Rebutato son de septiembre de ese año. Se trata de dos propuestas para colonizar la ladera de la montaña que baja hacia el mar con unas agrupaciones modulares de viviendas diseñadas a partir de la métrica del modulor a las que denominó Rob y Roq. Su justificación para promover agrupaciones de viviendas incluso en ese entorno tan especial se debía, como explicaría él mismo, a su intención de evitar la proliferación de las «ineficientes viviendas unifamiliares» ${ }^{35}$. A diferencia de la sabia ocupación del lugar que caracteriza a la E.1027 sutilmente girada respecto de los bancales

34. «Perhaps I misunderstand the underlying sense of your thoughts, as, even though you have lived in Paris for thirty years, you have not yet been able to make others comprehend your writing» LE CORBUSIER, carta a Badovici fechada el 1 de enero de 1950. Fundación Le Corbusier. (El fragmento en español está extraído del texto de Colomina, Beatriz., Op.cit., p. 51).

35. ZAKNIC, Ivan, op. cit., p. 56.

Feminismo/s 17, junio 2011, pp. 259-295 
existentes para optimizar la orientación y que «utiliza las terrazas-bancadas como parte integrante de la arquitectura de la casa aunque no se mimetiza con ellas ni en construcción, material o geometría ${ }^{36}$, en los proyectos de Rob y Roq los módulos se disponen linealmente en perpendicular a la línea de máxima pendiente del terreno. A causa de ello, el desnivel se maximiza debiendo recurrir a la solución inelegante de los pilotis de altura variable en contacto con el terreno bajo el primer forjado, además de acomodarse mucho peor a la orografía abrupta del lugar. La imagen más característica del proyecto se debe al motivo recurrente en la obra de Le Corbusier de las bóvedas a la catalana que aparece ya en algunas de sus primeras propuestas como las casas Monol de 1919 pero, sobre todo, entroncaba con su reciente mirada hacia la arquitectura vernácula como en su proyecto para una explotación agrícola en Cherchell (norte de África) de 1942, su proyecto en Sainte-Baume en los terrenos de su amigo Edouard Trouin ya en 1948 o las Maisons Jaoul terminadas en 1955 en Paris. Frampton se refiere al abandono de la estética moderna y a la sintaxis basada en la lógica del hormigón armado en sus proyectos posteriores a la segunda guerra mundial como una búsqueda de vincular su obra con la arquitectura vernacular:

Sin embargo, la 'a-racionalidad' de Le Corbusier iba más allá de la aplicación anacrónica, aunque expeditiva, de la bóveda a la catalana o la fábrica de ladrillo vista y el hormigón aplicado directamente en el encofrado de madera [...] La ventana arquetípica ya no era la fenêtre en longueur a través de la cual se miraba, sino una inserción enmarcada y con paneles a la que se miraba.

La solución constructiva de la cubierta a la catalana proyectada para las propuestas de Rob y Roq de Le Corbusier en Cap-Martin contrasta con la delicada cubierta plana de hormigón con vigas de canto invertidas y la doble piel diseñada por Gray y Badovici ${ }^{37}$ : «El forjado superior se ha construido con vigas invertidas, se ha podido colocar por encima un segundo forjado ligero de material cerámico con huecos que [...] constituyen un aislamiento perfecto para todas las temperies». Por otro lado, la sinceridad constructiva brutalista que caracterizaba la arquitectura de Le Corbusier en la posguerra con las huellas de los encofrados en el hormigón ya era anticipada en la E.1027 de 1926: «Esta disposición permite eliminar la escayola demasiado frágil para el techo

36. EsPegel, Carmen, Aires Modernos, Op. cit., p. 78.

37. GraY, Eileen, BADOviCI, Jean. «De l'Eclecticisme au doute». Londres, Da Capo Press, inc. \& Trewin Copplestone Publishing Ltd., vol. 1928-1929, 1975, y planchas pp.1738 y pp. 27-59, reproducción correspondientes a la monografía E.1027: Maison en bord de mer publicada en L'Architecture Vivante, número Otoño-invierno, (1929), Ed. Albert Morance, Paris. 
[que] está constituido por el forjado en bruto del desencofrado». ${ }^{38}$ Por otro lado, la disposición en paralelo hacia las vistas de la E.1027 y su apropiación del horizonte a través de la gran cristalera del salón que se abre a la terraza contrasta con la disposición en perpendicular y el encasillamiento de las vistas de la propuesta de Le Corbusier, si bien es cierto que ésta trata de maximizar el número de viviendas y por ello se adosan entre sí. El sintagma de la fenêtre en longueur es reelaborado con enorme soltura en la E.1027: una fachada de múltiples membranas en las que la horizontalidad queda enfatizada por el sistema de toldos que avanzan al primer plano de la fachada -a plomo con la barandilla- recortando el hueco rasgado horizontalmente cuando están desplegados, enmarcando con dicho gesto, la gran cristalera de la fachada sur que recorre la mayor parte de la fachada sur de suelo a techo.

Sin embargo, las propuestas de 1949 de Le Corbusier para Cap-Martin no pasarían de la fase de proyecto. Tuvo que esperar unos pocos años más hasta conseguir edificar algo allí, el cabanon, según él un regalo de cumpleaños para su mujer: su «pequeño castillo» en la Costa Azul como a él gustaba referirse con cierta dosis de ironía y ascetismo al mismo tiempo. Se trataba de una extraña cabaña de madera adosada a una pequeña tasca que regentaba RobertRebutato quien cedió el terreno a Le Corbusier, casualmente colindante ladera arriba con la parcela de la E.1027; algo que considerando los antecedentes no se puede pasar por alto. La elección del lugar no puede ser inocente, ¿por qué precisamente a escasos 20 metros de la E.1027? ¿no había ninguna otra parcela en todo el paraje? La primera decisión de proyecto para la Maison en bord de mer había sido precisamente la elección de un lugar que además de un espléndido paisaje tuviera el requisito de extraordinario aislamiento ${ }^{39}$, un lugar escogido por Gray "por ser inaccesible e invisible desde los alrededores» como recuerda Peter Adam. Colomina describe la actitud invasiva de la decisión en los siguientes términos: «Al imponer su visión desde arriba, estableció su dominio sobre el lugar de la casa de Gray. El cabanon no era más que una plataforma de observación, una especie de caseta de perro guardián $»^{40}$.

38. Gray, Eileen, BAdOvici, Jean., «De l'Eclecticisme au doute», Op. Cit., Ibidem.

39. A pesar de que Gray condujese coche (e incluso fuese una de las pioneras en pilotar aeroplanos ya desde 1913), la elección del lugar incluía la inaccesibilidad con el coche; como señala Espegel (Aires Modernos, op. cit., p.86) «La vivienda es una máquina separada del mundo a través de una cierta distancia que debe recorrerse a pie». Si a eso añadimos que tampoco se incluye el teléfono a pesar de que la vivienda disfruta de las instalaciones domésticas más avanzadas de la época la intención de aislamiento es definitiva.

40. Colomina, Beatriz, Op. cit. p. 50. [la cursiva es mía]. 
Es bien sabido que una de las formas recurrentes de los conquistadores para simbolizar su conquista ha sido apropiarse de sus lugares sagrados e imponer su propio símbolo de credo sobre ellos. Ejemplos a lo largo de la historia podemos encontrarlos en todas las culturas y civilizaciones; acaso uno de los más notables lo encontremos en la Mezquita-Catedral de Córdoba por lo que tiene de simbólico y de doble profanación. Sobre la catedral de San Vicente de la época visigótica -de la que no se deja nada- mandó Abderrahman I construir la mezquita que fue sucesivamente ampliada. A su vez, sobre parte de la mezquita se erige la actual catedral en distintas etapas desde la reconquista de Córdoba hasta el siglo XVI, constituyendo el símbolo arquitectónico más claro de la Reconquista ${ }^{41}$.

Si además de considerar el cabanon pensamos que a escasos metros Le Corbusier terminaría edificando las Unité de Camping en 1957 la elección del lugar no puede ser casual. La posición dominante ladera abajo sobre el diseño de Gray queda enfatizada por la importancia que otorgaba a los huecos hacia las vistas desde cabanon que en sus primeros bosquejos aparecen figuras erguidas mirando hacia el exterior, algunas de ellas con prismáticos ${ }^{42}$. La provocación añadida que suponía la elección del lugar y su proximidad a la E.1027 no pasó inadvertida para Gray; como apunta Adam: «Eileen always deeply resented this further intrusion. She pretended not to understand what he had contended with this simple attractive modular house. She called it 'that awful shack'». Es evidente que el conjunto de intervenciones proyectadas o ejecutadas por Le Corbusier en Cap-Martin evidencian una actitud de apropiación o colonización del lugar intentando crear un marco corbusierano ${ }^{43}$ aunque el conjunto no resulte precisamente armonioso. La profanación del rincón de aislamiento de la E.1027 parece evidente, sin embargo ¿qué credo arquitectónico trataba de imponer el cabanon? Desde luego, no el canon de modernidad

41. La famosa frase atribuida a Carlos V a su visita a Córdoba «Habéis destruido lo que era único en el mundo, y habéis puesto en su lugar lo que se puede ver en todas partes» subraya la brutalidad de la intervención pero conviene recordar que la actual catedral ocupa en planta una parte menor que el resto de la mezquita. De la primera catedral de San Vicente, en cambio, parece ser que de lo único de lo que sirvió fue de material de construcción para la propia mezquita. Dos sensibilidades bien distintas, desde luego.

42. RAUlt, Jasmine, Op. cit., p. 162.

43. Espegel apunta refiriéndose a ello : «Este edificio [Unité de Camping] fue proyectado por Le Corbusier en 1957 en una propiedad de Robert Rebutato, que le había cedido otra pequeña parcela donde construyó el Cabanon. El estrecho y largo edificio del camping, de dos plantas construidas sobre pilotis, no sólo ha destruido el aislamiento visual de la E.1027 sino que ha creado, junto con el Cabanon, un marco corbusierano. Las pinturas murales con que el maestro suizo tatuó los muros de la E.1027 causan el mismo efecto.» (EsPEgEL, Carmen. Aires Modernos, Op. cit., p.25) 
que Le Corbusier había capitaneado: el cabanon era la negación de la modernidad, poco más que un prototipo industrializado disfrazado de log cabin, otra incoherencia más.

¿Cuál es, pues, el verdadero significado del cabanon?, ¿cómo quería que se interpretara Le Corbusier? En la actitud propagandística característica de los escritos de Le Corbusier el suizo se refería a la claridad proyectual que emanaba de su sistema modular generado a partir de la antropometría idealizada en el modulor. En el texto ${ }^{44}$ del nuevo sistema escribía:

El 30 de diciembre de 1951, en la esquina de una mesa de un pequeño chiringuito de la Costa Azul, dibujé, para regalárselo a mi mujer con motivo de su cumpleaños, los planos de una cabañita que al año siguiente construí sobre un peñasco batido por las olas. Estos planos (los míos) fueron hechos en 3/4 de hora. Son definitivos; nada fue cambiado; la cabañita fue realizada con una puesta en limpio de aquel dibujo. Gracias a El Modulor, la seguridad en el caminar fue total.

Sin embargo, la realidad no se ajustaba al relato interesado del texto. Puede que, en efecto la concepción inicial de la cabaña hubiera sido diseñada por Le Corbusier en los tres cuartos de hora a los que se refería (la verdad es que el proyecto tampoco tiene gran cosa), pero el desarrollo del proyecto mantuvo ocupadas hasta a cinco personas durante varios meses. Entre ellos estaban Jean Prouvé y Charles Barberis, dos pioneros del diseño industrial. Blanc ${ }^{45}$ sugiere que la idea original de Le Corbusier consistía en desarrollar 'un prototipo para su futura repetición en serie', una especie de unidad mínima de habitación prefabricada. El exterior basto y rudo apenas si llegaba a la estética de una cabaña realizada con troncos; el interior, en cambio, estaba tratado con esmero, cuidadosamente diseñado con contrachapados de madera y un cierto aire de sofisticación. Sin embargo, esta contradicción entre interior y exterior no parece evidenciar la predicada sinceridad constructiva. Tampoco el aspecto desaliñado y aparentemente rústico del exterior obedece a ese espíritu de sinceridad constructiva que el mito de la cabaña de Laugier -con el que a veces se ha asociado- parecía sugerir. La cabaña del abad, con los arquetipos estructurales de correa y pie derecho, había servido de justificación para la gramática de esqueleto y piel que Le Corbusier tanto había contribuido a definir. Blanc añade ${ }^{46}$ :

\footnotetext{
44. Le Corbusier, Le Modulor 2. Paris, Editions L'Architecture d'Aujourd'hui, 1950, p. 154. (Cit. por BlanC, Philippe. «Cabanon:Roquebrune-Cap-Martin, Francia», ARQ, 66, Agosto 2007, Universidad Católica de Chile, Chile, pp. 88-93).
}

45. BlanC, Philippe, 2007, op. cit., p. 88.

46. Blanc, Philippe, 2007, op. cit., p. 89. 
El Cabanon, en contraste con lo que su aspecto indica, fue completamente prefabricado y minuciosamente supervisado por el arquitecto. Su fabricación se realizó en los talleres de Barberis en Ajaccio, en Córcega. Fue transportado en piezas por vía marítima desde Ajaccio y luego por tren hasta la estación de Cap-Martin. Rebutato se encargó del transporte de las piezas hasta el terreno de La Estrella de Mar.

El cabanon no se puede entender más que como patología. Nada de lo que hay en él responde a los cánones del dictado corbusierano. De los cinco puntos de la arquitectura no queda ni tan siquiera el rescoldo; hasta el proverbial desmembramiento en esqueleto y piel se ve traicionado al utilizar los troncos de madera ${ }^{47}$ como cerramiento y estructura portante de forma indiferenciada. Pero si lo analizamos en clave de su variada producción coetánea -la Unité d'Habitation en Marsella, la casa del Doctor Curruchet en Río de la Plata, la Villa Shodhan en Ahmedabad o incluso su polémica Capilla de Ronchampresulta completamente inaudito ${ }^{48}$ :

What impulses came together in this 'final dwelling'? Noble savage? Walden Pond? Mount Athos Monk? Was this cabin a solution to the frugal Simplicity, the perfect «communality discipline' of the monastic life that had so attracted him ever since his first visit to the Carthusian monastery outside Florence in $1907 ?$

Intentar atribuir al cabanon una nobleza arquitectónica de la que carece emparentándolo con Thoreau, Rosseau o con la vida monástica de los ortodoxos del Monte Athos no resulta razonable y desde un punto de vista crítico es insostenible.

Pretender que las reducidas dimensiones puedan mermar la calidad arquitectónica no es un argumento válido; espacios de dimensiones similares han conseguido una calidad incomparable (ver por ejemplo lo que consigue Sou Fujimoto en $15 \mathrm{~m}^{2}$ con su Wood House, en Kumamura; refugio mínimo construido sinceramente en madera).

Por otro lado, analizada fríamente la cabaña de Le Corbusier tiene demasiadas imperfecciones (Figs. 5 y 6): la extraña conexión con la tasca de Rebutato, la angostura del vestíbulo con esa puerta, su alineación con respecto al paso a la zona «vividera» (es mucho decir) que se inmiscuye en la privacidad puesto que visualmente se conecta con la zona de dormir, la ausencia de una puerta que independizara el vestíbulo de la zona vividera, el espacio para el

47. Hubo una fase durante el desarrollo del proyecto en la que el cerramiento proyectado estaba acabado con chapa de aluminio pero finalmente se adoptó el tratamiento con troncos de madera (ZAKNIC, Ivan, op. cit., p. 57).

48. ZAKNIC, Ivan, op. cit., Ibidem. 


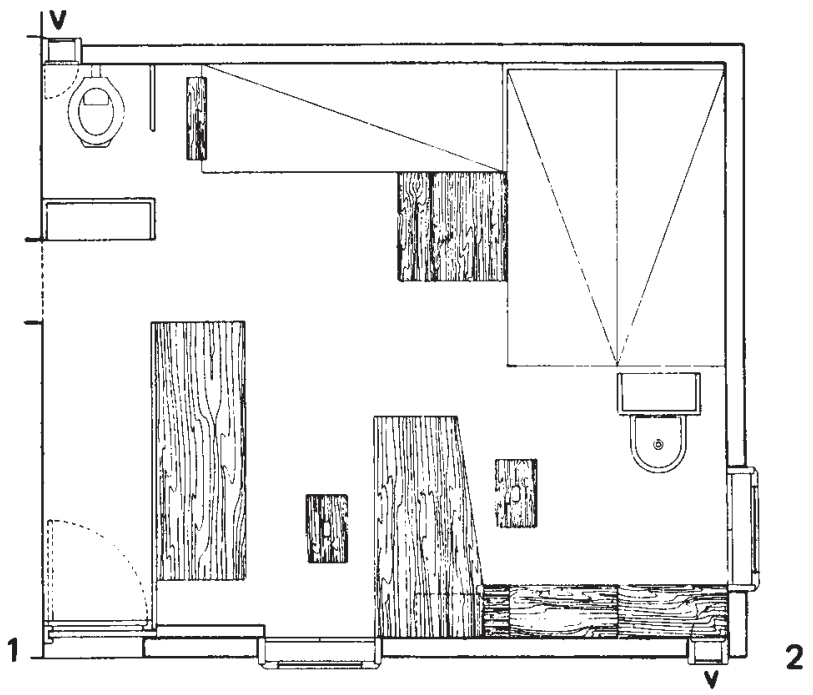

Fig. 5. Planta del Cabanon de Le Corbusier. (plano publicado en Le Corbusier, Willy Boesiger)

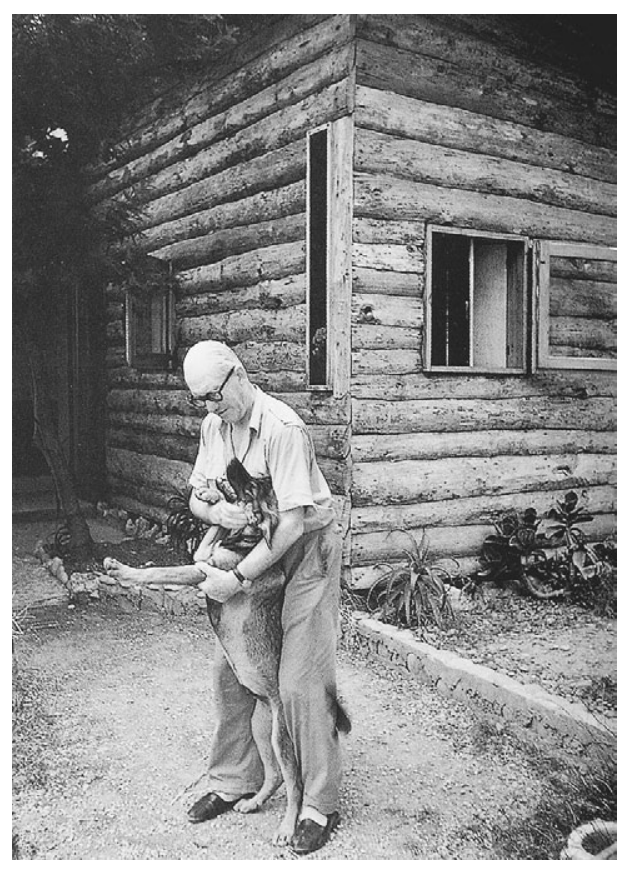

Fig. 6. Le Corbusier frente a su Cabanon.

(foto publicada en «Cabanon: Roquebrune-Cap-Martin, Francia», Philippe Blanc) 
inodoro cuyas dimensiones estrictas son innecesarias, por no mencionar las cuestiones de ventilación y el hecho de que dé directamente al espacio vividero habiendo como hay un vestíbulo al que podría conectarse para evitar dicha relación, la proximidad de la cama al aseo -con el cabecero cerca-, la ausencia de ducha, la falta de coherencia en el tratamiento de los materiales al exterior -la piel de troncos, el remate de la cubierta con chapa ondulada y el cuidado tratamiento interior con contrachapados de madera-, etc.

Todo lo que rodea a las intervenciones de Le Corbusier en Cap-Martin parece inexplicable. La referencia al vernáculo de una historia de arquitectura popular que había alimentado buena parte de su actividad durante los años 40 tampoco es sostenible, ¿a qué arquitectura vernacular se refiere el cabanon? ¿a las casas de madera escandinavas o a las $\log$ cabin de los colonos norteamericanos?; desde luego no al vernáculo mediterráneo, otro desprecio más hacia el lugar. El fingido aislamiento monacal en el que Le Corbusier se recluye miserablemente (y con él recluye a su mujer, Yvonne) en su «mon château» supone otra contradictio in terminis con su adosamiento parasitario a la tasca de Rebutato que únicamente suple la ausencia de cocina en su refugio mínimo pero no autosuficiente. Lo cierto es que Le Corbusier tras la muerte de su mujer y desde que la E.1027 estuvo en «manos amigas» pasaba allí temporadas enteras hasta su muerte: debía estar mejor en su interior que en su château. En todo caso, aún pudiendo justificar por la benignidad de la climatología estival que el mirador natural en el exterior fuera la verdadera «arquitectura» vividera y no proyectada del cabanon, relegando éste a un mero interior a modo de refugio mínimo, tampoco su tratamiento al exterior o la ausencia de algún lugar sotechado como protección frente al fuerte sol veraniego justifican la solución adoptada.

El contraste del cabanon con la sutileza de la E.1027 no puede ser mayor; tiene cierta lógica pensar que una influyó en el otro y quizás, de forma inconsciente, Le Corbusier estuviera respondiendo a muchas de las cuestiones planteadas por el diseño de Gray, un diseño que era sutilmente crítico con los preceptos del canon corbusierano de los años 20. El nombre de la Unité de Camping construida por Le Corbusier en 1957 junto a la cabaña ies una referencia al 'le style camping' de Gray o una denominación confusa? El objetivo declarado por Gray de maximizar el confort en un espacio mínimo ${ }^{49}$ ¿es también cuestionado por las reducidas dimensiones de su cabanon? No hemos querido comparar la arquitectura de la E.1027 y el cabanon porque

49. Gray escribía después a propósito de la E.1027 «House envisaged from a social point of view: minimum of space, maximum comfort» Gray archive, Victoria and Albert Museum, London (cit. por Constant, Caroline. Op. cit., p.269). 


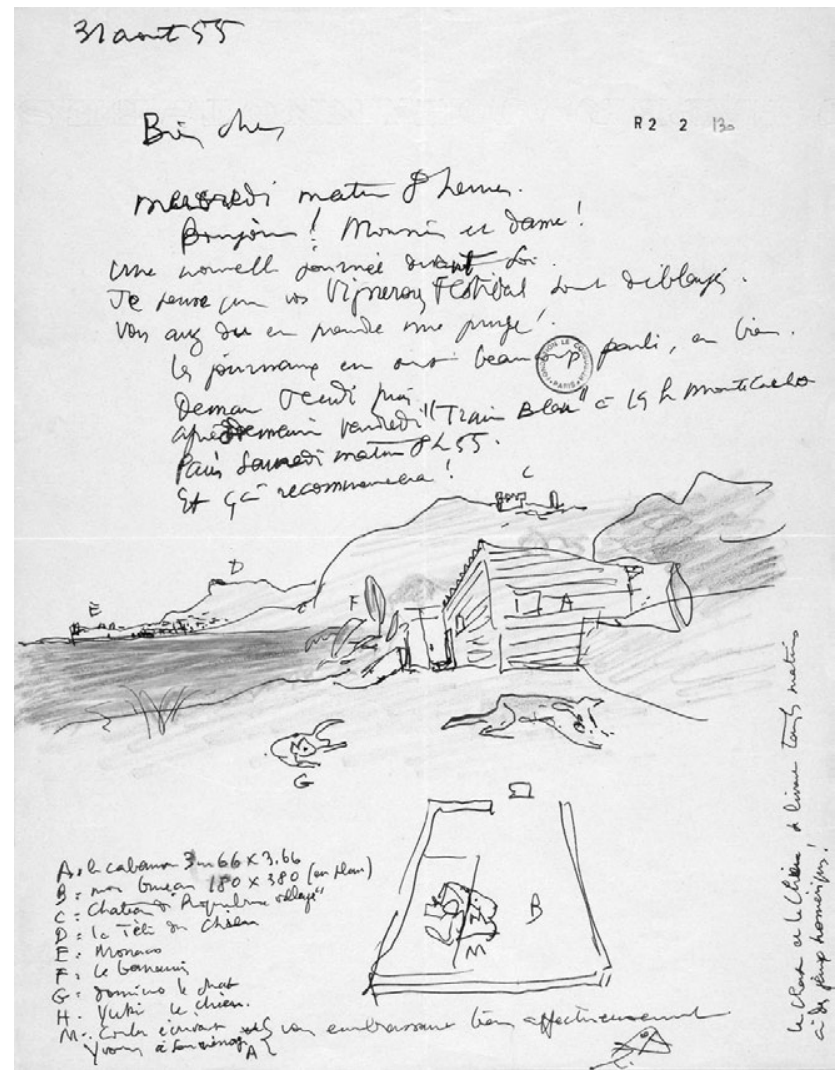

Fig. 7. Carta de Le Corbusier a su hermano 31 de agosto de 1955. (publicada en «Cabanon: Roquebrune-Cap-Martin, Francia», Philippe Blanc)

sencillamente son planteamientos y escalas que resultan incomparables. Obviar su conexión, por otro lado, aunque sea en el nivel del subconsciente, parece aventurado. Quizás la mala conciencia de Le Corbusier pueda explicar cómo quiso negar permanentemente una presencia tan obvia como la de la E.1027 a escasos 20 metros de su cabanon. Incluso en un dibujo que hace en una carta ${ }^{50}$ dirigida a su hermano aparece la cabaña ligeramente esbozada en el entorno donde se apuntan todas las referencias más claras en el lugar (el mar, Montecarlo, el Castillo de Roquebrune, la «cara de perro»-una cima montañosa que se divisa en la lejanía-); se incluyen incluso una platanera, su

50. LE CORBUSIER, Carta dirigida a su hermano fechada el 31 de agosto de 1955 (ver BLANC, Philippe, 2007, op. cit., p. 93). 
gato, su perro, y hasta la planta de su barraca de trabajo ${ }^{51}$ en la que se retrata a sí mismo dibujando. A pesar de lo descriptivo del dibujo y de las anotaciones con letras del alfabeto que apoyan la narración de lo dibujado con la correspondiente leyenda, se omite la E.1027, que debería aparecer en la visual hacia Montecarlo.

Respecto de las manipulaciones a las que nos referíamos antes son variadas y algunas de ellas contaron con la colaboración necesaria de la historiografía de la modernidad que, en buena medida, había estado alineada con los postulados de Le Corbusier durante años ${ }^{52}$. No nos detendremos demasiado en ellas pues resultan de mayor interés sus intervenciones arquitectónicas en contraste con la E.1027. La manipulación comienza desde el momento de la publicación de los murales de Le Corbusier en 1946 y 1948 en la que, como ya hemos tenido ocasión de comentar, no se hacía referencia alguna al nombre de Eileen Gray como autora de la villa. En la revista Interiors en el número correspondiente a junio de 1948 en la que se publica un artículo con el título «Le Corbusier, muralist» en los pies de foto de los murales se leía: «Murales, interiores y exteriores, ejecutados en técnica de grafito sobre yeso blanco, en una casa diseñada por Le Corbusier y P. Jeanneret, Cap. Martin, 1938 ${ }^{53}$. Parece poco probable que fuera Badovici quien facilitara las fotografías después de la polémica que tanta amargura le había producido, por lo que ¿quién si no Le Corbusier facilitó a la publicación las fotos de los murales? ¿Fue acaso ajeno a la manipulación -por omisión- sobre la autoría? Durante años la crítica atribuyó en exclusiva a Badovici la autoría de la casa, a pesar de que en la primera publicación de la misma en L'Architecture Vivante en el número monográfico de otoño-invierno de 1929 dedicado a la E.1027: Maison en bord de mer, quedaba clara la coautoría de la misma. Todavía en 1981 en la revista Casa Vogue, en el no. 119 se lee: «Firmatta Eileen Gray y Le Corbusier» y se atribuye la autoría de un sofá diseñado por Gray al propio Le Corbusier ${ }^{54}$. Sta-

51. Un cobertizo aparentemente prefabricado que hizo colocar tiempo después a unos metros de su refugio mínimo para poder trabajar que contribuía aún más a degradar el preciado lugar. Otra incoherencia más de su actividad en Cap Martin: la mayor parte del cabanon está destinado a lugar de trabajo sin embargo Le Corbusier tuvo que añadir la segunda caseta para poder trabajar. Incluso el cobertizo para los útiles de jardinería proyectado en chapa por Gray en su E.1027 es más digno y más sincero constructivamente que el cabanon, no pretende ser nada distinto de lo que realmente es.

52. TOURnikiotis, Panayotis. La historiografía de la arquitectura moderna. Madrid. Ed. Mairea/Celeste, 2001. (Tit. Orig. The Historiography of modern Architecture, Massachusetts Institute of Technology, 1999)

53. Colomina, Beatriz, op. cit. p. 50.

54. Colomina, Beatriz, op. cit. Ibidem. 
nislaus von Moos pensaba que Le Corbusier había tomado parte activa en el diseño de la villa ${ }^{55}$ sobre la que había escrito a propósito de los murales ¡cómo no $!^{56}$. Por otro lado, en muchas de las historiografías la vivienda o no aparece o ni siquiera se nombra a Eileen Gray como es fácil de comprobar; tal vez la sombra de Le Corbusier sobre la arquitectura de papel fuera tan alargada como la proyección pública de su propia arquitectura.

Las manipulaciones continuaron sobre el objeto de deseo fuera de los textos especializados en el ámbito material años después cuando, tras la muerte intestada de Jean Badovici, la propiedad pasó a manos de una hermana monja que vivía en Rumanía que no tenía interés en la villa ${ }^{57}$. Le Corbusier vio entonces la posibilidad de adquirir la vivienda o de conseguir que algún amigo se hiciera con ella, probablemente con objeto de salvaguardar sus preciados frescos como sugiere Constant ${ }^{58}$ :

Between 1958 and 1960 Le Corbusier actively sought «to find a solution for the purchase of the Badovici house» by soliciting potential buyers from Switzerland, explaining to Willy Boesiger that «some have thought of making a museum out of the house». His concern was clearly for the murals and their preservation rather than the fate of the house itself. In 1960 he contacted Madame Schelbert, sending her photographs, and that summer she purchased the villa.

Parece necesario subrayar cómo Le Corbusier sugiere a Willy Boesiger -conocido estudioso de su obra con quien tenía trato- que la E.1027 podría convertirse en museo, para contemplar sus murales claro está. Finalmente con la adquisición de la vivienda por parte de su amiga, Madame Schelbert, quien se haría finalmente con la propiedad. Pero conviene recordar cómo lo consiguió. Adam $^{59}$ se refiere al relato de la propia Schelbert en los siguientes términos:

Según testimonio de Mme. Schelbert, amiga próxima a Le Corbusier, cuando la casa salió a subasta pública en Menton cuatro personajes pujaron por ella, tres de los cuales eran: un enviado del Banco de Francia, Aristóteles Onassis y la propia Mme. Schelbert, que finalmente resultó la compradora. La cifra más alta la ofreció Onassis pero Le Corbusier, que había permanecido en la

55. EsPegel, Carmen, 2006, Op. Cit., p. 126.

56. Von Moos, Stanislaus. «Le Corbusier as a Painter», Oppositions, 19/20 (1980), p. 106. (cit. por EsPEgel, Carmen. Heroinas del espacio, Op. cit., p.126).

57. Aparentemente durante la dictadura comunista entonces en el poder, los ciudadanos rumanos no podían poseer propiedades en el extranjero y el dinero de la subasta fue recibido por un enviado del gobierno rumano <http://purecontemporary.blogs.com/ behind_the_curtains/2007/10/eileen-gray-1st.html>, consultado el 08-03-2011.

58. CONSTANT, Caroline, Op. cit., p. 279.

59. AdAm, Peter, Eileen Gray, Architect/designer: A Biography, Op. cit., pp. 359. (cit. por ESPEgEL, Carmen, Aires Modernos, op. cit, p. 8). 
sombra durante las negociaciones, desapareció un momento con el comisario $\mathrm{y}$, cinco minutos más tarde, la casa fue vendida a su amiga.

Le Corbusier había conseguido finalmente preservar sus murales con la adquisición de la casa por parte de Mme. Schelbert. Un dato más a propósito de la pugna entre Gray y Le Corbusier, incluso años después a propósito de la E.1027 lo apunta Adam ${ }^{60}$ indicando cómo se le prohibió expresamente a Eileen Gray que recogiera cualquier pieza de mobiliario, considerando que el mobiliario formaba parte integrante de la vivienda aunque, tiempo después, Le Corbusier le ofrecería dinero a Gray -hemos de suponer que a modo de compensación- que ella renunció aceptar. Pero ¿por qué le ofrecía dinero Le Corbusier a Gray si era Mme. Schelbert la que había adquirido en la subasta la vivienda con todos sus enseres? Quizás la respuesta pueda deberse al hecho de que durante sus últimos años de vida, Le Corbusier pasaba temporadas enteras en la E.1027 -gracias a la generosidad de su amiga también debemos suponer- y a finales del mismo año en que se subastó solicitó permiso a su nueva dueña para retocar sus murales, cosa que hizo. Adam ${ }^{61}$ también ha apuntado un detalle revelador a propósito de la manipulación de Le Corbusier: «For many years Mme. Schelbert thought that the house and the furniture were designed by Le Corbusier, and he never seemed to have corrected her impression», añadiendo otro dato relevante a propósito de lo que, enfrentamientos aparte, realmente pensaba Le Corbusier a propósito del diseño integral de la E.1027 entre arquitectura, interiorismo y mobiliario: «Mme. Schelbert had looked after the furniture. She always remembered Le Corbusier's dictum 'They are very special and rare'».

Parece evidente que la villa producía en Le Corbusier una verdadera obsesión que se prolongó a lo largo de toda su vida. La colonización de la E.1027 por medio de los murales no fue suficiente; el maestro también quiso batirse contra el reto en hormigón armado que suponía la construcción de la E.1027 como revisión crítica a muchos de sus planteamientos arquitectónicos en el plano de la arquitectura. Y así intentó llevar a cabo distintas intervenciones arquitectónicas alrededor de la Maison en bord de mer, casi todas ellas de dudoso valor. La presencia de la E.1027 integrándose y haciendo suyo el lugar para el que fue concebida ¿imponía demasiado incluso al arbiter elegantiorum de la modernidad o quizás todo se redujera a un problema de mala conciencia?

60. ADAM, Peter, 1989, Op. cit., p. 152.

61. ADAM, Peter, 1989, Op. cit., p. 152. 


\section{Crítica de género: la arquitectura de Eileen Gray en la E.1027}

Sin embargo, nos interesa aquí el plano de la arquitectura y las implicaciones que el espacio sofisticado y delicado de la E.1027 suponían, como crítica de facto a buena parte de los planteamientos de la línea corbusierana que acabaría imponiéndose entre las distintas corrientes que discurrían en el seno de la vanguardia arquitectónica de la época. Sólo así podemos entender la pugna entre Le Corbusier y Gray a propósito de la E.1027. Una pugna que sólo puede estar a la altura en lo que se refiere a su actividad pictórica, no en sus intervenciones arquitectónicas como hemos podido analizar. Sorprendentemente el Goliat de nuestra historia, el reputado maestro de la arquitectura, hubo de batirse con sus pinceles frente a un David convertido en arquitecto novel procedente del mundo del interiorismo y el diseño. Algo que recuerda vivamente la pugna entre Borromini y Bernini en la piazza Navona, con su Santa Agnese y la fuente de los Cuatro Ríos, respectivamente.

En lo referente a la autoría de la villa, si consideramos la manifiesta afinidad de planteamientos entre Badovici y la arquitectura de Le Corbusier de los años 20 y observamos la crítica sutil que la E. 1027 supone frente a ellos, parece lógico conceder el mayor protagonismo a Gray en el diseño de la misma. Lo

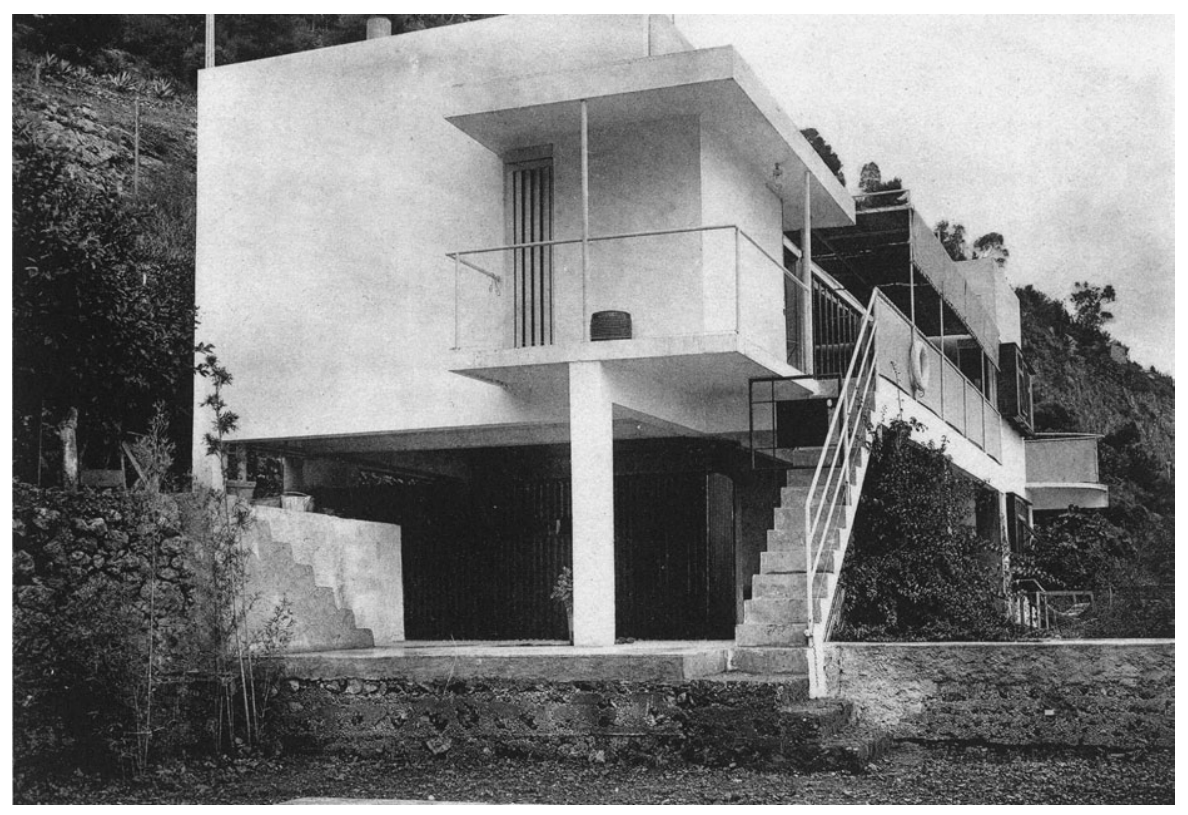

Fig. 8. E.1027 relación entre plantas y terraza cubierta «sous les pilotis». (foto publicada en L'Architecture Vivant, 1929) 
probable es que Badovici básicamente asesorase en las cuestiones técnicas por su formación y mayor experiencia como arquitecto, y el diseño global correspondiese a Gray, quien además estuvo al pie del cañón durante la ejecución de la obra de forma prácticamente exclusiva. Al parecer, Badovici contribuyó con las dos decisiones de proyecto que más vinculan la E.1027 con dos de los cinco preceptos corbusieranos ${ }^{62}$ : "Badovici suggested that the main living level be raised on pilotis and the spiral stair extended to the roof, its form derived from Vladimir Tatlin's Monument to the Third Internationale (1910-20)». Sin embargo, ni siquiera estos dos puntos son seguidos con el rigor establecido en el canon funcionalista. En efecto, el piano nobile de la vivienda está elevado sobre los pilotis de la planta inferior pero la planta únicamente queda liberada bajo el cuerpo principal de la edificación -la gran sala polivalente en la que se ha convertido el estar-, produciendo así una terraza cubierta al abrigo del sol mediterráneo, un espacio complementario al jardín al descubierto con el que se vincula apropiándose de las excelentes vistas al mar. Este recurso formal también puede vincularse con las villas palladianas y la arquitectura

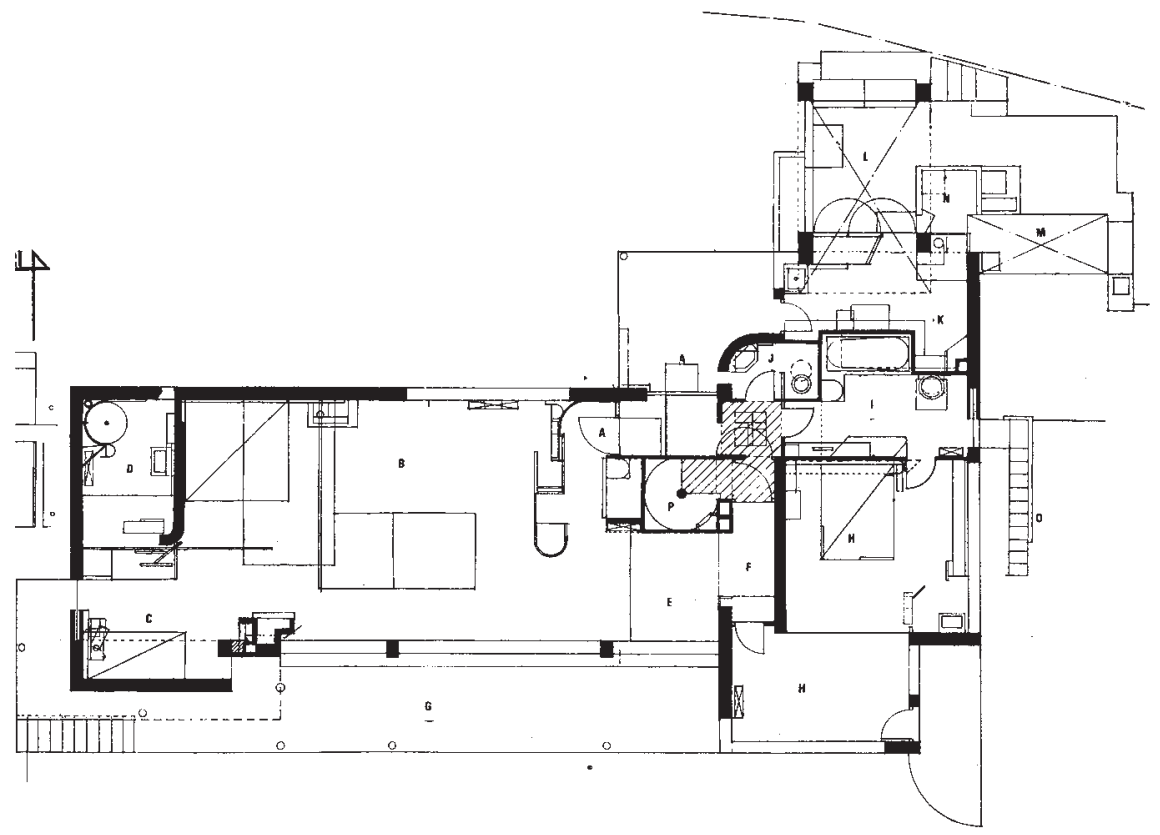

Fig. 9. Planta principal de la E.1027.

(publicada en Aires Modernos, Carmen Espegel)

62. Constant, Caroline, Op. cit., p. 269. 
palaciega renacentista; como en éstas, la entrada principal está en la cota del piano nobile.

La separación del volumen edificatorio principal del bancal superior -que se hizo coincidir con el nivel del piano nobile- produce una suerte de patio inglés que permite la ventilación cruzada por debajo de la terraza sous les pilotis y refuerza la separación de la promenade de acceso a la entrada del cuerpo edificatorio como gesto de privacidad. A pesar de la elevación de la planta principal sobre los pilotis, la sintaxis empleada en toda la casa es sobre todo muraria ${ }^{63}$, y mucho más vinculada a la articulación del espacio interior con el exterior, así como a los distintos usos que se van ordenando a partir de las estancias celulares que se agregan entre sí. La retórica está mucho más próxima -como casi toda la casa, si se estudia en profundidad- a la arquitectura De Stijl.

En cuanto a la cubierta ajardinada que se resuelve con el escultórico remate de la caja de escalera al atravesar el forjado de cubierta, como bien ha señalado Espegel ${ }^{64}$, tampoco se elabora mucho más allá que para facilitar su acceso:

La cubierta ajardinada está desprovista de relevancia funcional, ya que se encuentran en otras partes de la casa los elementos que la justificarían: solarium, terraza con vistas, jardín o umbráculo. La ausencia de peto o barandilla (tiene sólo un mínimo resalte para ocultar las pendientes de la cubierta) y de vegetación, le resta protagonismo como espacio vividero, aunque le confiere una mayor elegancia en el alzado.

Por otro lado, volcada como está la vivienda a la privacidad el «quinto alzado» que está constituido por la cubierta, de tener utilidad real, funcionaría como plataforma de exhibición, lo que contradeciría el planteamiento de partida; incluso el solarium se esconde en el jardín en uno de los bancales, a resguardo de las miradas indiscretas.

En cuanto a otro de los tres puntos canónicos, la planta libre, aquí está interpretada como articulación del espacio, y es evidentemente heredera de la arquitectura neoplasticista y de la «destrucción orgánica de la caja» de Wright; es decir a la descomposición de la forma cerrada. La apertura no es la consecuencia de haber desmembrado la arquitectura en estructura y cerramientos, como sucede en la arquitectura funcionalista, sino la elaboración

63. «La casa descansa sobre pilotis, si bien estos carecen de independencia al ser cuadrados, gruesos y pertenecer todavía al lenguaje del muro, al machón.», EsPEgEL, Carmen, Aires Modernos, Op. cit., p. 156.

64. Epegel, Carmen. Aires modernos. Op. cit., p. 156.

Feminismo/s 17, junio 2011, pp. 259-295 


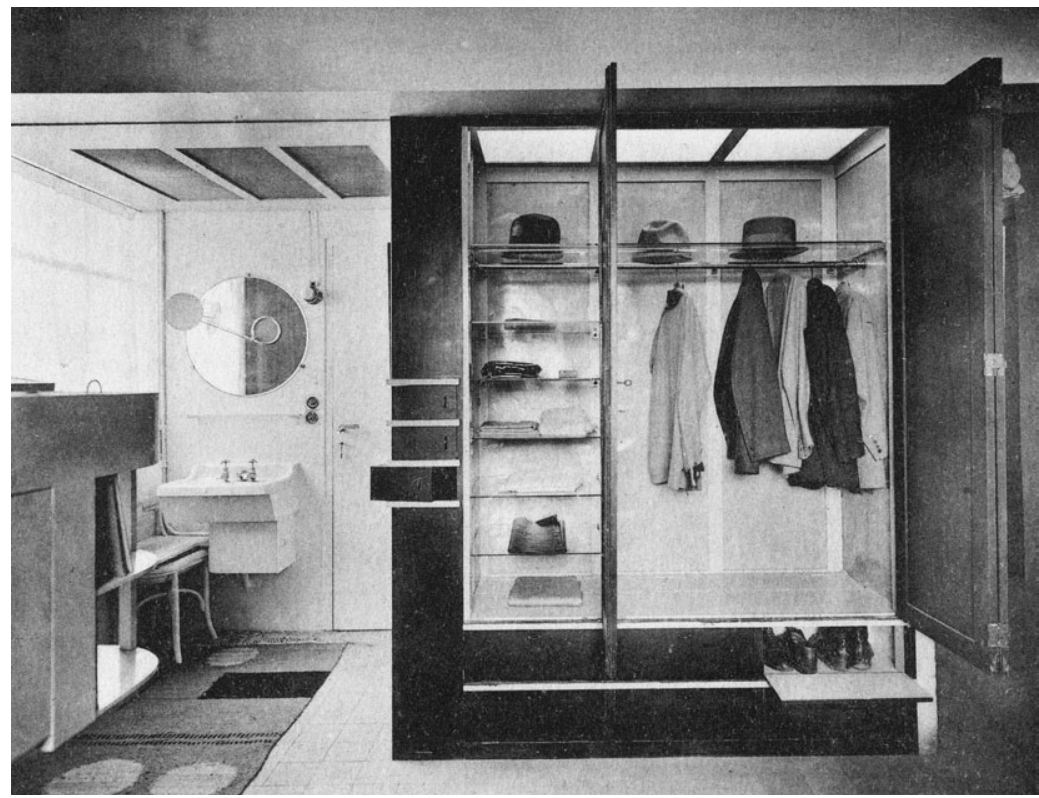

Fig. 10. Dormitorio de invitados. (publicada en Aires Modernos, Carmen Espegel)

de unos recorridos en torno a células funcionales que se ordenan a partir de distintos grados de privacidad y la resolución de las tensiones con el lugar ${ }^{65}$ :

Both interior and exterior of E.1027are characterized by a new interdependence of the parts. Architectural components and furnishings are rarely perceived as bounded or distinct; rather, their presence is understood in relation to adjoining elements. Gray's fascination with opacity and indecipherability led her to focus on the surface of the elements, their colours, textures, and reflective qualities, rather than their profile, modelling, or placement in a legible space. She never isolated the individual element or made it represent the totality of the ensemble. The result is a richly realized totality of space.

La arquitectura de Gray no se puede entender sin esa concepción de obra de arte total -gesamtkunstwerk- de raíces musicales wagnerianas, pero que ya había anticipado Wright a principios de siglo en el campo de la arquitectura y que sería un ideal a abrazar en la época del diseño de la Bauhaus con grandes defensores como Gropius. Sin duda, sus orígenes como diseñadora e interiorista la habían hecho cultivar un aprecio por la calidad de los materiales, los

65. CONSTAnt, Caroline, Op. cit., p. 273. 
colores y las texturas que más tarde extendería a su actividad arquitectónica. Los límites entre sus piezas de mobiliario, sus detalles de interiorismo y su arquitectura son tan difusos que no hay una separación real entre unos y otros: todos conforman una elaborada polifonía. La relación de Gray con el neoplasticismo data de su relación con Oud y Wils quienes habían quedado cautivados con la riqueza de los materiales y las texturas empleadas en combinación con una marcada abstracción formal de carácter geométrico en su Boudoir Monte Carlo exhibido en el XIV Salon des Artistes Decorateurs en 1923 en París. El reconocimiento pronto supuso la publicación de algunos de sus diseños en la prestigiosa revista holandesa Wendigen. La aplicación de los principios neoplasticistas a su arquitectura ya aparece en su primer proyecto profesional -la casa para un Ingeniero- realizado inmediatamente antes de la E. $1027^{66}$ :

Employing selected components of Le Corbusier's Maison Citrohan -pilotis, strip Windows, and free plan- in a critical manner, she was inspired by Theo Van Doesburg's «sixteen points toward a plastic architecture» to reject the singular closed volumes and typological formal constructs of Le Corbusier's early theoretical projects in favour of dynamic balance of elements, capable of mediating the opposition between interior and exterior.

Por otro lado, la concepción corbusierana de la vivienda como machine d'habiter, también sería revisada críticamente por Eileen de manera clara. Para ella la arquitectura debía estar al servicio del individuo, pero además debía relacionarse con todo su ser; con su experiencia corporal, con la gravedad de su materialidad y así escribiría: «A house is not a machine to live in. It is the shell of a man, his extension, his release, his spiritual emanation. Not only its visual harmony, but its entire organization, all the terms of the work, combine to render it human in the most profound sense.» La referencia al precepto del maestro suizo parece bastante directa e inequívoca como para evidenciar su posición respecto de los fríos interiores del funcionalismo.

La fachada libre es interpretada en la E.1027 como consecuencia de la descomposición de la forma en planta; por tanto, es una consecuencia lógica que también se emparenta más con la arquitectura neoplasticista y el canon de Van Doesburg que con la idea de la fachada que se articula libremente por haber sido liberada de su función portante de Le Corbusier. La solución estructural de la E.1027 es de las partes más débiles del proyecto, si se la considera en términos de la rigidez normativa del modelo funcionalista pero no

66. Constant, Caroline, Op. cit., p. 268. 
lo es tanto si pensamos en la duplicidad de la carga repartida tanto en muros como en soportes.

Por último, respecto de la fenêtre en longuer, también aquí Gray da muestras sobradas de una interpretación libre del maestro suizo. Los huecos son variados, muchos de ellos con voluntad de rasgarse horizontalmente, sin embargo la transición del exterior al interior está sumamente elaborada. Una sucesión de filtros y membranas separan el exterior de la terraza principal hacia el interior de la gran sala. El gran hueco se rasga prácticamente a lo largo de la fachada sur del estar pero también se rasga verticalmente de suelo a techo. Al exterior, la única fachada que realmente tiene la villa -sólo visible desde el mar-, la imagen de los toldos desplegados sugieren la horizontalidad de la fenêtre en longuer que acompaña la tensión horizontal que anima toda la composición. Sin embargo, este es sólo el primer filtro que gradúa la intensidad del soleamiento en la terraza y en el interior de la vivienda. El gesto de rasgar hasta el suelo el hueco únicamente en la zona más pública indica también una dosificación en los grados de privacidad y la voluntad de vincular esta estancia con el entrono próximo y el encuentro de las rocas con el mar. Por otro lado, la ventana con carpinterías en acordeón permite abrir la sala completamente a la terraza y con ello apropiarse más íntimamente del lugar aún desde el interior de la villa.

En la E.1027, las tensiones con el lugar se resuelven a partir de la articulación libre en planta en el sentido descompositivo. Así, interior y exterior se entrelazan sugiriendo itinerarios que recuerdan la idea de Le Corbusier de promenade architecturale. A este respecto conviene recordar lo que escribe Van Doesburg ${ }^{67}$ respecto de la relación entre huecos y muros, exterior e interior:

La nueva arquitectura ha horadado la pared, suprimiendo así la dualidad interior- exterior. Las paredes ya no sostienen, se han convertido en puntos de apoyo. De ello resulta una planta nueva, una planta abierta; totalmente distinta de la del clasicismo, porque los espacios interiores y exteriores se penetran [entrelazan].

Solo que en el paseo arquitectónico de Gray -y a diferencia de lo que sucede en Le Corbusier- no está concebido como una sucesión visual de imágenes que convenientemente encuadradas por la arquitectura articulan el recorrido. Se trata más de la interpenetración entre el exterior y el interior lo que establece relaciones entre las vistas y los usos por un lado, y entre el individuo

67. VAn Doesburg, Theo. «La evolución de la arquitectura moderna en Holanda», Principios del nuevo arte plástico y otros escritos. Murcia, Ed. C.O.A.T.M., 1985 (Tit. Orig. Grondbegrippen van de nieuwe beeldende kunst; Tijdschrift voor Wijsbegeerte XIII, 1919), p. 115. 
y su habitar cada uno de los espacios, por otro, lo que genera el recorrido tanto por dentro como por fuera de la vivienda. Así la propia Gray expresaría su desacuerdo respecto del reduccionismo visual en el entendimiento de la arquitectura: «The art of the engineer is not enough if it is not guided by the primitive needs of men. Reason without instinct. We must mistrust merely pictorial elements if they are not assimilated by instinct», en palabras que bien podrían ir dirigidas al maestro suizo.

Buena parte de la crítica que se ha hecho al Estilo Internacional tiene que ver con su insensibilidad para con el lugar -sobre todo en el caso de las propuestas urbanísticas-. El ejemplo de Le Corbusier resulta paradigmático en este sentido, pero incluso su visión idealizada de una arquitectura modélica también tenía cierto sentido de desapego respecto del lugar sobre el que se actuaba. La E.1027 se acomoda y hace suyo el lugar de muchas maneras, la casa no podría estar en otro sitio distinto del que está. Quizás sean las circulaciones el punto más débil de la casa, cómo se resuelve el ingreso en la casa en un zaguán cubierto pero abierto que obliga a varias puertas o, acaso más grave sea la desvinculación de ambas cocinas -en especial la de invierno- a algún paso interior. Quizás conviene recordar las sabias reflexiones de Espegel ${ }^{68}$ respecto del valor de la E.1027:

La Maison en bord de mer consigue su identidad insertándose en la tradición (no formal) mediterránea, bebiendo de ella sus logros esenciales, y en cierta manera reinventándola; pero es auténtica en la fidelidad que guarda consigo misma y con su tiempo (Movimiento Moderno, hormigón armado, planta libre, imagen marítima) [...] El proyecto se utiliza como arma de distinción y de resistencia contra la uniformidad cartesiana moderna que niega toda tradición.

Resulta paradójico el final de la E 1027. Su restauración reciente -por parte del gobierno francés que finalmente adquirió la vivienda- dado que se encontraba en muy malas condiciones de conservación se debe a la existencia de los polémicos murales de Le Corbusier; en la actualidad sólo se conservan cinco de ellos. Tal vez, después de todo, quien hizo bastante por ocultar, manipular y desfigurar el diseño original de la villa ha contribuido de forma fortuita a la preservación de la E.1027. Quizás, en un futuro soñado podamos imaginar la villa restaurada y liberada de la carga figurativa de los murales de Le Corbusier que, con la actual tecnología, podrían ser trasladados para restaurar el sentido original de la obra tal como la proyectó Gray.

68. Espegel, Carmen, Aires Modernos, Op. cit., p. 268. 
La buena arquitectura como la buena crítica no tiene género porque se centra en el objeto -la cosa en $\mathrm{si}^{69}{ }^{69}$; el género es introducido cuando el sujeto -que sí lo tiene- usurpa la objetividad del análisis imponiendo su visión personal en el hecho interpretativo. Si en esta historia ha de prevalecer una crítica de género, creo que debe ser la que Eileen Gray realizó con el diseño y la construcción de la E.1027 sobre los rígidos cánones en los que Le Corbusier y la crítica afín a sus postulados trataron de encorsetar la riqueza polifónica del Movimiento Moderno, no la de sus intérpretes.

\section{Referencias bibliográficas}

ADAM, Peter. «Eileen Gray and Le Corbusier», 9H, 8(1989,) pp. 150-153.

ADAM, Peter. Eileen Gray, Architect/designer: A Biography (Rev. Ed.). Londres, Ed. Thames and Hudson, 2000 (1987).

BADovicI, Jean, «Peinture Murale ou Peinture Spatiale.», L'Architecture d'Adjourd'hui, 8, no , 3 (1937).

BADOVICI, Jean, carta a Le Corbusier, fechada el 2 de julio de 1941, Fundación Le Corbusier.

BLanc, Philippe. «Cabanon:Roquebrune-Cap-Martin, Francia», ARQ, 66, Agosto 2007, Universidad Católica de Chile, Chile, pp. 88-93

Colomina, Beatriz, «Líneas de Batalla: E. 1027», en Pasajes, $2^{\circ}$ semestre 2001, Univ. de Buenos Aires. Centro de Estudios Amancio Williams., pp. 47-55.

CONSTANT, Caroline. "The Nonheroic Modernism of Eileen Gray», Journal of the Society of Architectural Historians, Vol. 53, Nº. 3 (Sep. 1994), pp. 265-279.

ESPEGEL, Carmen. Aires modernos. E. 1027: maison en bord de mer Eileen Gray y Jean Badovici 1926-1929. Madrid, Ed. Mairea Libros, 2010

EsPegel, Carmen. Heroinas del espacio. Mujeres arquitectos en el Movimiento Moderno. Valencia, Ed. Generales de la Construcción, 2006.

GrAY, Eileen, BADOviCI, Jean. «De l'Eclecticisme au doute». Londres, Da Capo Press, inc. \& Trewin Copplestone Publishing Ltd., vol. 1928-1929, 1975, y planchas pp.17-38 y pp. 27-59 (reimpresión de la monografía E.1027: Maison en bord de mer publicada en L'Architecture Vivante, número Otoño-invierno, (1929), Ed. Albert Morance, Paris).

69. MiRAndA, Antonio, 2008, Columnas para la resistencia. Madrid, Ed. Mairea. Hubiera sido deseable en aras de la crítica y de acuerdo con los principios enunciados por Miranda -de quien me reconozco deudor- haber dedicado más extensión al juicio crítico sobre la propia E.1027 que a los hechos y las peripecias que rodean a la E.1027 y a sus autores con el propio Le Corbusier. Sin embargo, el artículo trata de desvelar, en primera instancia, las razones de la actitud de Le Corbusier y de la crítica para con la E.1027, lo que ha obligado a exponer y analizar detenidamente los hechos para apuntar las causas que los originaron; las limitaciones de extensión han producido el resto. 
LE CORBUSIER, «Unité», L'Architecture d'Adjourd'hui, 19, 1948.

LE Corbusier, carta a Badovici fechada el 1 de enero de 1950. Fundación Le Corbusier.

Le Corbusier, Le Modulor 2. Paris, Editions L'Architecture d'Aujourd'hui, 1950, p. 154.

Miranda, Antonio, 2008, Columnas para la resistencia. Madrid, Ed. Mairea

RaUlT, Jasmine. «Occupying E.1027. Reconsidering Le Corbusier's «Gift» to Eileen Gray, Space and Culture, Vol. 8, 2 (May 2005), pp. 160-179.

RYKWERT, Joseph. «Eileen Gray: two Houses and an Interior, 1926-1933», Perspecta, Vol. 13/14 (1971), pp. 67-73.

TOURNIKIOTIS, Panayotis. La historiografía de la arquitectura moderna. Madrid. Ed. Mairea/Celeste, 2001. (Tit. Orig. The Historiography of modern Architecture, Massachusetts Institute of Technology, 1999).

VAn Doesburg, Theo. «La evolución de la arquitectura moderna en Holanda», Principios del nuevo arte plástico y otros escritos. Murcia, Ed. C.O.A.T.M., 1985 (Tit. Orig. Grondbegrippen van de nieuwe beeldende kunst; Tijdschrift voor Wijsbegeerte XIII, 1919), p. 115.

ZAKNIC, Ivan. «Le Corbusier Sans Fin», Journal of Architectural Education, Vol. 42, 3 (Spring 1989), pp. 49-59.

<http://purecontemporary.blogs.com/behind_the_curtains/2007/10/eileen-gray1st.html>, consultado el 08-03-2011. 